\title{
THE DOW CHEMICAL COMPANY REPORT
}

NINIH QUARTERLY REPORT

(DECEMBER 1, 1951 - FEBRUARY 29, 1952)

U. S. ATOMIC ENERGY COMMISSION

CONTRACT NO. AT $(11-1) 60$

PREPARATION OF HIGH PURITY MAGNESIUM AND A STUDY OF THE EFFECT OF NON-METALLIC AND ALKALI METAL IMPURITIES ON THE CORROSION CHARACTERISTICS OF PURE MAGNESIUM

Signature Date

I have read this copy of this report

Signature

Date

Signature

Date 


\section{DISCLAIMER}

This report was prepared as an account of work sponsored by an agency of the United States Government. Neither the United States Government nor any agency Thereof, nor any of their employees, makes any warranty, express or implied, or assumes any legal liability or responsibility for the accuracy, completeness, or usefulness of any information, apparatus, product, or process disclosed, or represents that its use would not infringe privately owned rights. Reference herein to any specific commercial product, process, or service by trade name, trademark, manufacturer, or otherwise does not necessarily constitute or imply its endorsement, recommendation, or favoring by the United States Government or any agency thereof. The views and opinions of authors expressed herein do not necessarily state or reflect those of the United States Government or any agency thereof. 


\section{DISCLAIMER}

Portions of this document may be illegible in electronic image products. Images are produced from the best available original document. 
$\underline{0}$

$$
600-88
$$

THE DOW CHEMICAL DOMPANY METALLURGICAL LABORATORIES

(i)

$$
\begin{gathered}
\text { NINTH Quarterly Report } \\
\text { (December 1; } 1951 \text { - February } 29 \text {, 1952) } \\
\text { U. S. ATOMIC ENRGY COMMISSION } \\
\text { CONTRACT NO. AT (11-1) 60 }
\end{gathered}
$$

\section{PREPARATION OF HIGH PURITY MAGNESIUM AND A STUDY OF THE EFFECT OF NON-METALIIC AND ALKALI. METAL IMPURITIES ON THE CORROSION CHARACTERISTICS OF PURE MAGNESIUM}

\section{Copies to:}

U. S. Atomic Energy Commission (75)

The Dow Chemical Company (16) 


\section{$1, \quad 000-88$ \\ DISTRIBUTION LIST FOR CONTRACT NO. AT (11-1)60}

Argonne National Laboratory

P. 0. Box 5207

Chicago 80, IIIinois

(Attn: Dr. Hoylande D. Young)

U. S. Atomic Energy Commission

1901 Constitution Avenue, N. W. Washington 25, D. C.

(Attn: B. M. Fry)

Battelle Memorial Institute

505 King Avenue

Columbus, Ohio

(Attn: Dr. H. W. Russel)

Brookhaven National Laboratory

Information \& Publication Division

Documents Section

Upton, New. York

(Attn: Miss Mary E. Vaisman)

Bureau of Ships

Code 390

Navy Department

Washington 25, D. C.

(Attn: Miss Mattie L. Houghton)

Carbide \& Carbon Chemicals Division-2

- Plant Records Department

Centrai Files $(\mathrm{K}-25)$

P. O. Box P

Oak Ridge, Tennessee

Carbide \& Carbon Chemicals Division-2

- Central Reports \& Information Office

P. 0. Box P

. Oak Ridge, Tennessee

$(Y-12)$

U. S. Atomic Energy Commission

Chicago Operations Office

- P. 0. Box 6140-A

Chicago 80, IIlinois

(Attn: Research Service Division)

General Electric Company

Technical Services Division

Technical Information Group

P. 0. Box 100

Richland, Washington

(Attn: Miss M. G. Freidank)
-4 U. S. Atomic Energy Commission - I

Hanford Operations office

P. 0. Box 550

Richland, Washington

(Attn: Technical Information

Library)

Knolls Atomic Power Laboratory -3 P. 0. Box 1072

Schenectady, New York

- 1 (Attn: Document Librarian)

Los Alamos Scientific Laboratory-2

P. 0. Box 1663

Los Alamos, New Mexico

-3 (Attn: Document Custodian)

Massachusetts Institute of Technology

Hood Building

155 Massachusetts Avenue

-1 Cambridge 39, Massachusetts

(Attn: Dr. A. R. Kaufmanm)

Mound Laboratory

U. S. Atomic Energy Commission

P. 0. Box 32

Miamisburg, Ohio

(Attn: Dr. M. M. Haring)

National Advisory Committee for Aeronautics

Aircraft Engine Research Laboratory

Cleveland Airport

Cleveland, Ohio

(Attn: Dr. Robert F. Selden)

-1 National Bureau of Standards -2

U. S. Department of Commerce

Coordinator of Atomic Energy

Project, Division IV

Washington 25, D. C.

(Attn: Dr. R. D. Huntoon)

Office of Air Force Plant

Representative

Air Material Command

NEPA Division, Fairchild

Engine and Airplane Corp.

P. O. Box E

Oak Ridge, Tennessee

(Attn: Major D. J. Grant) 


\section{DISTRIBUTION LIST FOR CONTRACT NO. AT (11-1):60}

Iowa State College

P. 0. Box 14A, station A

Ames, Iowa

(Attn: Dr. F. H. Spedding)

North American Aviation, Inc.

Atomic Energy Research Department

P. 0. Box 309

Downey, California

(Attn: Dr. Chauncey Starr)

Oak Ridge National Laboratory

P. O. BoX P

Oak Ridge, Tennessee

(Attn: Central Files)

Chief, Patent Branch

U. S. Atomic Energy Commission

1901 Constitution Avenue, N. W. Washington 25, D. C.

(Attn: Roland A. Anderson)

Sandia Corporation

Sandia Base

Classified Document Division

Albuquerque, New Mexico

(Attn: Mr. Dale N. Evans)

Sylvania Electric Products, Inc. - I

P. 0. Box 6

Bayside, L. I., New York

(Attn: Miss Garda Steiner)

U. S. Atomic Energy Commission

- Library Branch, Technical Information Division, ORE

P. O. BoX $\mathbf{E}$

Oak Ridge, Tennessee

University of California Radiation Laboratory

Information Division

Room 128, Building 50

Berkeley, California

(Attn: Dr. R. K. Wakerling)

Westinghouse Electric Corporation -2 Atomic Power Division

P. 0. Box 1468

Pittsburgh 30 , Pennsylvania

- (Attn: Librarian) $-1$

-1 U. S. Atomic Energy Cominission -3

New York Operations Office

P. 0. Box 30, Ansonia Station

New York 23, New York

(Attn: Division of Technical

Information)

Office of Naval Research

Navy Department

Washington $25, \mathrm{D}$. C.

(Attn: Code 423)

Dr. Cyril s. Smith

Institute for the Study of Metals

University of Chicago

Chicago, Illinois

Dr. Maxwell Gensamer

Professor of Metallurgy

Columbia University

New York 27, New York

-1 Dr. B. S. Old

Arthur D. Little, Inc.

30 Memorial Drive

Cambridge 42, Massachusetts

Dr. J. B. Johnson

Chief, Metallurgical Group

Wright-Patterson Air Force Base

Dayton, Ohio

Dr. M. G. Fontana

Ohio State University

Columbus, Ohio

Dr. R. F. MehI

Carnegie Institute of Technology

Pittsburgh, Pennsylvania

Dr. W. A. Patrick

John Hopkins University

Baltimore, Maryland

Dr. H. H. Uhlig

Massachusetts Institute of Technology

Cambridge, Massachusetts

Dr. H. J. Read State College, Pennsylvania 


$$
-3-\ldots 000-88
$$

DISTRIBUTION LIST FOR CONTRACT NO. AT(11-1)60

Office of Naval Research Chief of Naval Research Navy Department

Washington $25, \mathrm{D}$; C. (Attn: Code 252)
- I -.. Chief, Metallurgy \& Matterials Branch Division of Research U. S. Atomic Energy Commission Washington $25, \bar{D}$. C. 
Abstract- - . - . - . - . - . . . . - 1 Introduction - . . - . . . . . . . . . 2 Summary of Experimental Results - - - . - - . - . - 2 Conclusions _ . . . . . . . . . . . . . . . 4 Results and Discussion- - - - - - - - - - - - - 5

A. Contamination Studies- - - - - - - - - - 5

1. Mg-Fe System - - - $\ldots \ldots$

2. $\mathrm{Mg}-\mathrm{C}$ and $\mathrm{Mg}-\mathrm{Fe}-\mathrm{C} \ldots \ldots$

3. $\mathrm{Mg}-\mathrm{Si}$ and $\mathrm{Mg}-\mathrm{Fe}-\mathrm{Si} \ldots \ldots \ldots$

4. Chloride Contamination - - - - - - - - - 10

5. Solution Potential Measurements- - . - . - - II

6. Effect of Thermal History on Iron Analyses - - 12 a. Extrusion - - - . - - - - - - - 12 b. Casting- - - - - - - - - - - 13

B. Purification Studies - _ - . . - . . . . 13

1. Vacuum Sublimation-Argon Casting Unit- - - - - 13 a. Summary of Operations- - - . - - - - - 13 b. Analysis of Purified Magnesium - - - - - 14 c. Cooling Rate of SVC Metal- _ - _ - - - 15 d. Observed Corrosion Rates of High-Purity $\mathrm{Mg}-15$ 2. Tantalum-Lined Purification Unit - - - - - - 18 3. Arc-Melting of Sublimed Magnesium - - - - - 19 a. Apparatus and Procedure- - - - - - - 19 b. Analysis Results _ - - . - . - . - - 19 c. Metallographic Examination - - - - - - 20 d. Corrosion Results - . - . . . . - - 20

References

Tables

Figures 


\section{APPENDIX A}

Tahie I - Numerical Listing of Magnesium Alloy Analyses. Table II - Detailed Corrosion and Solution Potential Data.

Table III- Sublimation Data and Operating Conditions.

Figure 1 - Effect of Cooling Rate on Corrosion Rate of Mg-Fe Alloys.

c - Thiee Hour Corrosion Exposure Data on Rapidly Cooled $\mathrm{Mg}-\mathrm{Fe}$ Alloys.

3 - One Day Corrosion Exposure Data on Rapialy Cooled $\mathrm{Mg}-\mathrm{Fe}$ Alloys.

$4 \& 5$ - Photographs of Rapidly Cooled Mg-Fe Corrosion Specimens ( 3 hour exposure).

6 - Photographs of Rapidly Cooled Mg-Fe Corrosion Specimens (I day exposure).

7 - Comparison of Fast and Slow Cooled Mg-Fe Corrosion Specimens.

8 - Comparison of Mg-Fe Corrosion Specimen Quenched from Above and Below Solidus.

9.- Solution Potentials - Mg-Fe Alloys.

10 - Effect of Carbon on the Corrosion Rate of Sublimed Mg.

11 - Effect of Carbon on the Corrosion Rate of Mg-.00.2\% Fe.

12 - Effect of Carbon on the Corrosion Rate of $\mathrm{Mg}-.0066 \% \mathrm{Fe}$.

13 - Effect of Carbon on the Solution Potential of Sublimed $\mathrm{Mg}$ and $\mathrm{Mg}-\mathrm{Fe}$ Alloys.

14 - Effect of Silicon on the Corrosion Rate of Sublimed Mg.

15 - Effect of Silicon on the Corrosion Rate of Mg-.0022\% Fe.

16 - Effect of Silicon on the Corrosion Rate of Mg-.0077\% Fe.

17 - Effect of Silicon on the Solution Potential of Sublimed Mg.

18 - Effect of Silicon on the Solution Potential of Mg-.0022\% Fe.

19 - Effect of Silicon on the Solution Potential of $\mathrm{Mg}-.0077 \% \mathrm{Fe}$.

20 - Effect of Phosphorus on the Solution Potential of Sublimed $\mathrm{Mg}$.

21 - Effect of Chloride Content on the Corrosion Rate of Sublimed $\mathrm{Mg}$.

22 - Effect of Casting Temperature on the Spectrographic Analyses of Iron.

23 - Sketch of Arc-Melting Pot.

24 - Cooling Curve for SVC Metal (Sublimed-Argon Cast Mg).

25 - Photomicrograph of Triply-Sublimed and Arc-Melted Mg. 


\section{6 $100-88$}

NINTH Quarterly Report

(December 1, 1951 - February 29, 1952)

U. S. ATOMIC ENERGY COMMISSION

CONTRACT NO. AT $(11-1) 60$

\section{PREPARATION OF HIGH PURITY MAGNESIUM AND A STUDY OF THE EFFECT OF NON-METALLIC AND ALKALI METAL IMPURITIES ON THE CORROSION CHARACTERISTICS \\ OF PURE MAGNESIUM}

\section{ABSTRACT:}

Corrosion studies of the magnesium iron binary system indicate that the corrosion properties are significantly affected by the thermal history during casting./ Three distinct types of thermal history are now recognized: 1. slow cooling ( $\leqq 2000^{\circ} \mathrm{F}$ ) min.) from the pouring temperature; 2. rapid cooling (cold water quench $\sim 11000^{\circ} \mathrm{F} / \mathrm{min}$.) from the liquid state; 3 . slow cooling ( $\sim 100 \% \mathrm{~F} / \mathrm{min}$.$) through the solidus temperature followed$ immediately by rapid quenching ( $\sim 8000^{\circ} \mathrm{F} / \mathrm{min} .-\mathrm{cold}$ water quench). The slow_cooling results in a tolerance limit for iron in magneslum of $\sim 60^{\circ} \mathrm{ppm} F \mathrm{Fe}$. Alloys rapidly cooled from the liquid state have corrosion rates which are markedly improved over their slowly cooled counterparts. Nevertheless, they still show increases in corrosion rate above $60 \mathrm{ppm} \mathrm{Fe}$. The third type of treatment has not been completely explored, but limited tests indicate that the corrosion rates for this treatment are relatively low and that a high tolerance limit similar to that of Hanawalt, Nelson, and Peloubet ${ }^{l}$ may be observed. The solution potential measurements of $\mathrm{Mg}-\mathrm{Fe}$ alloys also show a definite relationship to thermal history.

Corrosion evaluation of slowly cooled ( $\leqslant 2000^{\circ} \mathrm{F} / \mathrm{min}$.) $\mathrm{Mg}-\mathrm{Fe}-\mathrm{Si}$ alloys revealed that $200 \mathrm{ppm}$ silicon was significantly detrimental to the corrosion properties of pure magnesium containing $22 \mathrm{ppm} F$. Similarly, $2500 \mathrm{ppm}$ silicon produced increased corrosion rates in the presence of $9 \mathrm{ppm} \mathrm{Fe}$. On the other hand, , silicon additions were beneficial in alloys containing $77 \mathrm{ppm} \mathrm{Fe}$. Silicon had no effect on the solution potential of the lower iron content alloys, but did result in significant increases in the higher iron content alloys ( $77 \mathrm{ppm}$ ). 
Investigations of the $\mathrm{Mg}-\mathrm{C}$ and $\mathrm{Mg}-\mathrm{Fe}-\mathrm{C}$ systems revealed considerable segregation of the carbon as determined by chemical analyses. In spite of the high corrosion rates in certain cases, an evaluation of the data showed no definite evidence that carbon additions (10-140 ppm lampblack) are detrimental:

Re-evaluation of the corrosion properties of the $\mathrm{Mg}-\mathrm{Cl}$ system refuted the conclusion drawn in the 4 th quarter attributIng increased corrosion rates in $3 \% \mathrm{NaCl}$ to high chloride content.

Vacuum sublimation and argon casting was further investigated as a purification method for magnesium. It was not possible to correlate impurity content with corrosion rate of the high-purity metal. Certain physical factors not yet adequately defined may be masking the effect of impurity on the corrosion rate. Arc-melting of sublimed magnesium can be accomplished on a small scale, but the melt is slightly contaminated during the process.

\section{INTRODUCTION:}

The purpose of this investigation is to prepare high. purity magnesium and to study the effect of non-metallic and alkali metal impurities on the corrosion characteristics of high purity magnesium. The first two years of the contract period were devoted primarily to a detailed study of purification by sublimation and to determine the effect of various nonmetálic and alkali metal additions on the corrosion characteristics of pure binary magnesium alloys. During the 9 th quarter the contamination studies were broadened to include the $\mathrm{Mg}-\mathrm{Fe}$ system and ternary alloys of magnesium, iron and non-metallics. The pronounced effect of thermal history on the corrosion properties necessitated a study of this factor, particularly in the case of alloys containing minor amounts of iron (as low as $10 \mathrm{ppm}$ ).

\section{SUMMARY OF EXPERIMENTAL RESULTS:}

The corrosion properties of magnesium-iron alloys are remarkably sensitive to thermal history as a result of casting and heat treatment. Slowly (air) cooled alloys show increased 
corrosion rates at iron contents as low.as $30 \mathrm{ppm}$, although the tolerance limit is considered to be at $60 \mathrm{ppm}$. If the alloys are rapidly cooled by water quenching from the liquid state, vastly improved corrosion properties are obtained although somewhat increased corrosion rates prevali at and above approximately $60 \mathrm{ppm}$ Fe (Fig. 1). This treatment also results in corrosion rates having a higher degres of scatter at the higher iron con tents (140-310 ppm) than does slow cooling. By allowing the alloys to cool slowly ( 100\% F./min.) through the solidus temperature before quenching, the corrosion characteristics were improved to an even greater extent than by the quench from the liquid (Fig. 8). Thermal history affects not only the corrosion characteristics, but also the solution potential of the $\mathrm{Mg}-\mathrm{Fe}$ alloys. For example, the quenched alloys undergo a $5 \mathrm{mv}$ decrease in potential upon increasing the iron content from 6 to $150 \mathrm{ppm}$ while slow cooling results in an $50 \mathrm{mv}$ decrease with similar Fe contents.

Additions of silicon to $\mathrm{Mg}-\mathrm{Fe}$ alloys may have a beneficial or detrimental effect upon the corrosion properties, depending upon the iron content of the alloys. Corrosion results indicate that silicon is in jurious in alloys containing iron below the tolerance limit (Figs. 14, 15). Here silicon contents above 1000 ppm with $9 \mathrm{ppm}$ iron or $150 \mathrm{ppm}$ in the presence of $22 \mathrm{ppm}$ iron result in increased corrosion rates. On the other hand, all silicon additions made to alloys containing $77 \mathrm{ppm}$ iron (above tolerance limit) result in decreased corrosion rates (Fig. 16). In these higher iron alloys, increasing the silicon from 60 to $4800 \mathrm{ppm}$ produced significant increases in the solution potential ( 1.648 to $1.660 \mathrm{mv}$ ). In contrast, silicon additions had no effect on the solution potential of lower iron content alloys ( 6 and $22 \mathrm{ppm}$ ).

The corrosion results of alloys containing 6,20 , and 66 ppm Fe with varying amounts of carbon (25-140 ppm lampblack), showed no high corrosion rates directly attributable to the carbon content. Similarly, the solution potential did not decrease as a result of increased carbon contents. Alloys contaminated with chlorides behaved in a similar manner to the carbon alzoys since no harmful effect was detected in the $3 \% \mathrm{NaCl}$ corrosion tests. 
Phosphorus additions (12-4500 ppm) produced no change in the solution potential values of magnesium-phosphorus alloys in contragt to the sizeable effects previously noted in the Mg-Fe-P alloys. (Fig. 25, Biennial Report \#COO-85).

Triple sublimation and argon casting of magnesium effectively reduces the iron content to 1 or $2 \mathrm{ppm}$ as evaluated by chemical and neutron activation analyses, but falrly high carbon contents result. Corrosion rates of the sublimed and cast material appear to be influenced by certain physical factors such as cold working, thermal history, and surface roughness.

Arc-melting of triply-sublimed magnesium on a hearth of the same material was carried out in an attempt to produce a metal free from metallic impurity. The melt is contaminated with iron, manganese, and probably some oxide.

CONCLUSIONS:

\section{Mg-Fe System: .}

It has been demonstrated that the cooling rates of the magnesium-iron alloys have a pronounced effect on their corrosion characteristics (Fig. I). Furthermore, the tolerance limit for iron in magnesium as well as the solution potential values are changed by thermal history. A detailed metallographic study of the quenched alloys must be made before an explanation of these results is possible. Explanation of the vast differences in corrosion behavior between $\mathrm{Mg}-\mathrm{Fe}$ alloys quenched from below and above the freezing point (Fig. 8) requires careful metallographic studies and possibly a determination of the phase diagram for this compositional region. The corrosion properties of $\mathrm{Mg}-\mathrm{Fe}$ alloys quenched from temperatures below the freezing point should be investigated further.

\section{Mg-Fe-Si System:}

Silicon is detrimental to the corrosion characteristics of pure magnesium containing lron below the tolerance limit ( $60 \mathrm{ppm}$ ), but salutary to alloys containing iron above the tolerance limit. No explanation for the deleterious effects of silicon in the presence of small amounts of iron is offered. 
Comparison of the Mg-Fe-P alloys with the higher iron-silicon alloys suggests that the improved corrosion properties of the latter alloys may result from increased solubility of the-cathodic second phase in the presence of silicon. The proposed metallographic examination of this system might clarify the role of silicon in the corrosion process.

\section{$\mathrm{Mg}-\mathrm{Fe}-\mathrm{C}$ System:}

Carbon (25-140 ppm) apparently had no harmful effect on the corrosion properties of high purity magnesium containing iron. This conclusion is proposed tentatively since only a limited amount of carbon (lampblack) could be introduced into the metal. Further exploration of this alloy system is believed necessary in view of the erratic corrosion results obtained on the SAC (SublimationArgon (ast) metal obtained in the purification program. Evaluation of the corrosion behavior of alloys containing $\sim 40 \mathrm{ppm}$ iron and varying carbon should reveal the effect of carbon on the tolerance limit for iron.

\section{Mg-Cl System:-}

Chlorides introduced into pure magnesium as \#230 flux have no effect on the $3 \% \mathrm{NaCl}$ corrosion properties provided the metal is free of other impurities.

Multiple sublimation and argon casting is effective in reducing the iron content of magnesium to 1 or 2 parts per million.

RESULTS AND DISCUSSION: :

A. Contamination Studies:

1. Mg-Fe System:

$\mathrm{Mg}-\mathrm{Fe}$ corrosion studies have been continued in an attempt to rationalize the variations in the Fe tolerance reported previously by the authors and that of Hanawalt, Nelson, and Peloubet ${ }^{1}$... Earlier results of this project suggested a tolerance limit of $60 \mathrm{ppm} F e$, whereas Hanawalt et al reported $170 \mathrm{ppm}$. Thermal history appeared to be the most probable source of the se tolerance limit variations since the casting techniques differed markedly. The first group of $\mathrm{Mg}-\mathrm{Fe}$ alloys prepared for this 
project were poured at a temperature of $800^{\circ} \mathrm{C}$. into a split graphite mold, resulting in a cooling rate of approximately $2000^{\circ} \mathrm{F}$./minute. Hanawalt, Nelson, and Peloubet allowed their alloys to cool slowly in the crucible through the solidus temperature; subsequently quenched them in a stream of running water, producing an estimated cooling rate of $\sim 10000^{\circ} \mathrm{F} / \mathrm{min}$. Greater solution of the cathodic second phase material (iron) would bo expected from this type of treatment than from a slower cool. It is also conceivable that rapid cooling rates might result in better corrosion rates and account for a higher tolerance limit. The validity of the thermal history hypothesis was tested on a series of iron alloys quenched in still water from the melting point, giving a cooling rate of $11,000 \% \mathrm{~F} / \mathrm{min}$. The rapidity of the cooling rate during quenching should result in a supersaturated solid solution of $\mathrm{Fe}$ in $\mathrm{Mg}$.

Corrosion tests of these alloys revealed that the alloys above $95 \mathrm{ppm} \mathrm{Fe}$ had two distinct zones which exhibited decidedly different corrosion rates. The exterior layer of the specimens which froze first was relatively resistant to corrosion in $3 \%$ $\mathrm{NaCl}$ while the interior of the specimens was seriously attacked. This behavior suggested that the interior of the specimens was liquid when quenched, whereas the exterior was solid before the quench. Additional melts purposely quenched from above and below the melting point substantiated this explanation. Quenching from the partially solidified state produced ingots with an exterior shell possessing high corrosion resistance and an interior which was rapidly attacked. On the other hand, alloys completely solidified before quenching showed no variation in the corrosion pattern, being generally quite corrosion resistant. Apparently, the cooling rate at or above the freezing point is as important as the cooling rate below the freezing point. The optimum conditions for enhanced corrosion resistance, appear to be a relatively slow cool through the freezing point followed immediately by a water quench.

Figure 1 illustrates the effect of thermal history on the corrosion characteristics of the $\mathrm{Mg}-\mathrm{Fe}$ system. These data 
show that the critical iron range $(90-200 \mathrm{ppm})$ obtained on slower cooling ( $2000^{\circ} \mathrm{F} . / \mathrm{min}$ ) ) is largely eliminated by rapid quenching $\left(11,000^{\circ} \mathrm{F} . / \mathrm{min}\right.$.) of the metal from the partially solidified condition. However, it was noted that the thermal history had no effect on the corrosion rates at the higher iron contents, 230-310 ppm, since the curves coincide in this range. The increased scatter in the experimental points obtained with the 3 hour alternate immersion exposure tests (3\% NaCl) shown in Figure 2 for the quenched alloys may be attributed to the increased difficulty of obtaining reproducible rapid cooling rates. Higher Fe contents with similar thermal histories yield an apparently erratic corrosion behavior (cf. Fig. 2 and 3). However, aditional work is necessary for clarification. Variations noted in the thermal history of alloys \#70659 and \#70656 have resulted in elimination of the corrosion data on these alloys from Figures 1,2 , and 3 .

Although the present data has not revealed a tolerance limit for $F e$ as high as $170 \mathrm{ppm}^{1}$ consideration of the effect of thermal history on the corrosion characteristics would suggest that the tolerance limit may vary. It is anticipated that a series of $\mathrm{Mg}-\mathrm{Fe}$ alloys cooled slowly through the freezing point and immediately quenched in cold water will furnish data closely par alleling the earlier results.

The corrosion characteristics obtained on slow air cooling $\left(50^{\circ} \mathrm{F} . / \mathrm{min}.\right)$ or casting into a graphite mold $\left(2000^{\circ} \mathrm{F} \cdot / \mathrm{min}\right.$ ) ) are similar (See Fig. I) in the iron range studied (35-100 ppm). In these cases increased corrosion rates are obtained if an iron content of $=60 \mathrm{ppm}$ is attained. Similarly, if the iron content exceeds $60 \mathrm{ppm}$ in alloys quenched from the partially solidified state, increased corrosion rates will also be obtained but the increases will be decidedly less than for the slowly cooled alloys. The appearance of the corrosion specimens subsequent to 3 hour and 1 day alternate immersion exposures in $3 \% \mathrm{NaCl}$ are shown in Figures 4, 5, and 6. Close examination of the se figures will show a duplex structure exhibiting considerably different types of corrosion resistance in the higher iron content alloys. Rapldiy cooled and slowly cooled alloys containing 99 ppm Fe, illustrated in Figure 7 , demonstrate the beneficial effect of 
quenching the alloys. The variation in the corrosion properties of alloys containing $175 \mathrm{ppm}$ Fe quenched from the solid and semi-solid state is shown in Figure 8 . The improvement in corrosion resistance obtained by quenching after complete solidification is forcibly presented in this photograph.

If the tolerance limit of $170 \mathrm{ppm}$ is as sumed to be correct for rapid cooling, the tolerance limit for iron in magnesium must be controlled by the thermal history. Additional work will be necessary to prove this point conclusively.

Solution potential studies of the $\mathrm{Mg}-\mathrm{Fe}$ alloys were conducted concurrently with the corrosion tests and will be discussed in a later section of the report.

2. $\mathrm{Mg}-\mathrm{C}$ and $\mathrm{Mg}-\mathrm{Fe}-\mathrm{C}$ :

A series of Mg-C alloys were prepared by addition of equal parts of \#230 flux (mixed chlorides) and lampblack to sublimed magnesium which contained approximately 9 ppm iron. Corrosion tests of the se alloys gave erratic results which did. not appear to be simply related to the carbon content. (Fig. 10). The considerable spread encountered with specimens having duplicate carbon analyses suggests that the erratic corrosion results may be attributed to segregation of the carbon additions which possess limited solubility in the magnesium. Detailed analyses of these alloys revealed that two compositions - (\#70398. and \#70402) - contained rather large amounts of chlorides. 760483 and 19- $140 \mathrm{ppm} \mathrm{Cl}$ respectively. This difference in chloride content might be causing the erratic corrosion behavior. However, subsequent work demonstrated that chloride aditions alone have little effect on the salt water corrosion characteristics of high purity magnesium, (FIg. 2I) (See section on chloride contamination). However, chlorides cannot be disregarded completely as a source of erratic corrosion behavior since combinations of carbon and chlorides or iron, carbon and chlorides may be detrimental to the corrosion properties of magnesium. More complex combinations of these constituents will be required to define their relationohip. In the subsequent alloy series of $\mathrm{Mg}-\mathrm{Fe}-\mathrm{C}$ (\#70385-70388, 70390-70394) attempts were made to prepare melts cont'aining 20 and 


$$
-9-14 \quad 000-88
$$

$40 \mathrm{ppm}$ Fe with varying amounts of carbon (lampblack). Analysis of the se alloys revealed average iron contents of 20 and $66 \mathrm{ppm}$ and average chloride contents of 7 and $10 \mathrm{ppm}-\infty$ the maximum reported chloride was $21 \mathrm{ppm}$. The widespread variations encountered suggested that segregation was present in the alloys.

The corrosion behavior of the lower iron alloys (Fig. 11) indicate that $130 \mathrm{ppm}$ carbon may be a silghtly injurious to the corrosion resistance of high purity magnesium containing $20 \mathrm{ppm}$ iron.

Since Iron contents on the order of $60 \mathrm{ppm}$ (tolerance limit for cooling rate of $2000^{\circ} \mathrm{F} / \mathrm{min}$.) give disproportionately large corrosion rates, it is unfortunate that attempts to make alloys containing 40 ppm Fe yielded an average iron content of $66 \mathrm{ppm} \mathrm{Fe}$. Consequently, the task of separating the combined effects of carbon and iron on the corrosion rate became more difficult. However, consideration of the data presented in Figure 12 leads to the conclusion that the corrosion values are readily explainable on the basis of the iron content. Apparently, $100 \mathrm{ppm}$ carbon have no detectable effect on the salt water corrosion resistance of pure magnesium containing $66 \mathrm{ppm}$ iron. A series of $\mathrm{Mg}-\mathrm{Fe}-\mathrm{C}$ alloys containing $40 \mathrm{ppm} \mathrm{Fe}$ will be necessary to decide whether the tolerance limit for iron in magnesium can be lowered by the presence of sultable amounts of carbon. Further work will include this series of tests.

\section{3. $\mathrm{Mg}-\mathrm{Si}$ and $\mathrm{Mg}-\mathrm{Fe}-\mathrm{Si}:$}

Powdered silic on additions $(3-660 \mathrm{ppm})$ were made to melts ( $\# 68270-68276$ ) of sublimed magnesium ( $4+5 \mathrm{ppm} F \mathrm{Fe}$ ) for the purpose 'of determining its effect on the corrosion properties. The corrosion data for the se alloys (Fig. 14) indicate that silicon above $1000 \mathrm{ppm}$ increased the corrosion rates. Because the alloys appear to pick up approximately $3 \mathrm{ppm} \mathrm{Fe/1000} \mathrm{ppm} \mathrm{Si。}$ some ambiguity exists as to whether the increased corrosion rates result from a lowered iron tolerance limit or from the detrimental influence of silicon in iron-free $\mathrm{Mg}$. If the former were true, a tolerance limit of $10 \mathrm{ppm}$ Fe would be indicated in the presence of $2500 \mathrm{ppm}$ silicon. However, justification for this argument may 
be found in Figure 15, which illustrates the effect of silicon on the corrosion properties of magnesium containing $22 \mathrm{ppm} F e$. Here it will be noted that the tolerance limit for silicon is only 150 $\mathrm{ppm}$ in the presence of $22 \mathrm{ppm}$ iron when the alloys are relatively slow cooled ( $2000^{\circ} \mathrm{F} . / \mathrm{min}$.).

When the iron content is above the tolerance limit ( $60 \mathrm{ppm}$ when cooled at $\left.=2000^{\circ} \mathrm{F} \cdot / \mathrm{min}.\right)$, the effect of silicon additions appears to be entirely beneficial, (Fig. 16). As this shows, the beneficial effects on the corrosion characteristics are nearly proportional to the magnitude of the silicon additions $(60-2300 \mathrm{ppm})$. Since these alloys exhibit decreasing corrosion. rates at $2300 \mathrm{ppm}$ silicon, the work will be extended to higher concentrations of silicon with the same iron content (77 ppm). Studies of the corrosion characteristics of the pure magnesiumsilicon binary system will be continued. A determination of the silicon tolerance limit in the presence of $40-50 \mathrm{ppm}$ Fe should also be informative. It is believed that the beneficial effects of silicon in the higher iron alloys may be a result of an increased solubility of the iron analogous to the previously reported effect of phosphorus. Microstructural studies of these alloys will be undertaken to confirm this idea.

4. Chloride Contamination:

Determination of the effect of chloride contamination on the corrosion behavior of sublimed magnesium was accomplished by additions of \#230 flux (Melts \#68409-68415). Alloys containing 40 to $2500 \mathrm{ppm}$ of chlorides with an average iron content of $7 \mathrm{ppm}$. were produced by casting the alloys without the usual setting period. The corrosion results and the scatter in analytical results shown in Figure 21 indicate that chlorides as high as 2500 ppm have no detrimental effect on the $3 \% \mathrm{NaCl}$ corrosion resistance even in the presence of $7 \mathrm{ppm} F$. These results show further that the high corrosion rates attributed to chloride content in the 4 th quarter (\#COO-21, Fig. $5 \& 6$ ) should probably be attributed to $F e+C I$ in conjunction with a relatively slow cool. A study of the $\mathrm{Mg}-\mathrm{Fe}-\mathrm{Cl}$ system is planned to determine whether or not chlorides plus minor amounts of iron (20-40 ppm) have a detrimentally adjitive effect on the corrosion properties of high purity magnesium. 
5. Solution Potential Measurements:

Solution potential measurements were made on the alloys prepared in recent quarters in order to determine what element and/or combination of elements produce alloys which are cathodic to high purity magnesium. It was thought that this data might aid in deciding which of those elements have a deleterious effect on the corrosion chararteristics of high purlty magnesium.

The non-metallics; silicon, carbon and phosphorus show no effect on the solution potential of pure magnesium (Figs. 13, 17, and 20). However, when a cathodic impurity such as iron is present, the effect of such elements can be quite marked. In the Mg-Fe-P alloys it has been reported (Biennial Report, \#COO-85) that phosphorus can raise or lower the solution potential values depending upon the iron content and the amount of phosphorus present. Below the iron tolerance limit ( $\sim 60 \mathrm{ppm}$ ) phosphomus effects are negligible; above this iron value the solution - potential is decreased by small amounts of phosphorus and increased by large amounts of phosphorus. Because these effects vary with iron content, the reader is referred to Figure 22 (Biennial Report, \#COO-85) for information on specific compositions. Silicon affects the solution potential of $\mathrm{Mg}-\mathrm{Fe}$ alloys in a similar manner to phosphorus in spite of its different corrosion behavior in alloys containing iron below the tolerance limit. Sllicon did not change the solution potential of alloys containing $22 \mathrm{ppm} F e$ (Fig. 18), but did increase the solution potential of alloys containing 77 ppm Fe (Fig. 19).

No effect of carbon on the solution potential values of $\mathrm{Mg}-\mathrm{Fe}$ alloys could be detected (Fig. 13) because of the limited range of carbon additions. Different results, however, might be expected if a method of adding greater amounts of carbon could be devised.

The solution potential values of $\mathrm{Mg}-\mathrm{Fe}$ alloys rapidly quenched $\left(11,000^{\circ} \mathrm{F} / \mathrm{min}\right.$.) from the partially solidified condition are shown in Figure 9. These data show a slight decrease ( $8 \mathrm{mv}$ ) in solution potential from $6-310 \mathrm{ppm} F$. This curve differs markedly from that obtained on a series of slow cooled (2000\%./min.) 
$\mathrm{Mg}-\mathrm{Fe}$ alloys (Fig. 22, Report-\#CO0-85). The implications of this pronounced difference in solution potentials are not clearly understood at this time since a metallographic study of the new alloys has not been completed. No differences in solution potentials between the interior and exterior of the specimens were detected in spite of the sizeable differences in corrosion behavior. More prooide data on the delalionship between the solution potential and the iron content (slow cooled alloys) would undoubtedly aid in a better understanding of the $\mathrm{Mg}-\mathrm{Fe}$ ternary corrosion data. Data on this relationship are currently being obtained in conjunction with corrosion data on alloys containing 40-100 ppm Fe.

6. Effect of Thermal History on Iron Analyses:

The non-reproducibility of iron analyses encountered in the earlier work resulted in considerable conjecture as to the cause of these discrepancies. Consequently, the effect of extruaing and casting $\mathrm{Mg}-\mathrm{Fe}$ alloys at various temperatures was investigated.

\section{a. Extrusion:}

No significant effect on the spectrographic analyses for iron was discovered by extruding two alloys containing different concentrations of iron at low or high temperature. see table below:

\begin{tabular}{|c|c|c|c|c|}
\hline Alloy No. & & Desc: & ription & $\begin{array}{l}\text { Spec. Fe } \\
\text { Anal. (ppm) }\end{array}$ \\
\hline 69320 & "As & Cast" & $\cdot$ & 330 \\
\hline $69.320-1$ & "As & Extruded" & $900^{\circ} \mathrm{F} \cdot($ nose $)$ & 330 \\
\hline$"-1$ & $"$ & $"$ & (butt) & $"$ \\
\hline $69320-2$ & " & $" 1$ & $650^{\circ} \mathrm{F} \cdot$ (nose) & 335 \\
\hline " -2 & $"$ & $"$ & (butt) & 330 \\
\hline 69324 & "As & Cast" & & 188 \\
\hline $69324-1$ & "As & Extruded" & $900^{\circ} \mathrm{F} \cdot($ nose $)$ & 188 \\
\hline$"-1$ & $"$ & 8 & (butt) & 190 \\
\hline $69324-2$ & $"$ & $\because$ & $650^{\circ} \mathrm{F} \cdot$ (nose) & 180 \\
\hline$" \quad-2$ & $"$ & $n$ & $" \quad$ (butt) & 200 \\
\hline
\end{tabular}


b. Casting:

An alloy (\#67515) containing approximately 310

ppm Fe was sampled with a pneumatic gun at $50^{\circ} \mathrm{F}$. intervals from 1200 to $1400 \% \mathrm{~F}$. The duplicate spectrographic analyses are plotted against increasing and decreasing temperature in Figure 22.

\begin{tabular}{|c|c|c|c|c|c|}
\hline Casting Temperature & 1200 & 1250 & 1300 & 1350 & $1400^{\circ} \mathrm{F}$. \\
\hline Iron Cuntent (ppm) & 320 & 315 & 305 & 335 & 315 \\
\hline (Increasing. Temp.) & 310 & 270 & 270 & 300 & 310 \\
\hline Iron Content (ppm) & 27.5 & 315 & 360 & 375 & \\
\hline (Decreasing Temp.) & 265 & 285 & 330 & 330 & \\
\hline Average $\mathrm{Fe}$ (ppm) & 293 & 296 & 316 & 335 & 313 \\
\hline $\begin{array}{l}\text { Average Standard Devi- } \\
\text { ation }(\sigma) \text { ppm Fe }\end{array}$ & 23 & 19 & 33 & 70 & 3 \\
\hline
\end{tabular}

The average analysis and average standard deviation calculated for each casting temperature are given in the above table. Comparison of these analytical results with those of the extruded alloys (preceding table), reveals a greater degree of scatter in the cast alloys. Since the analyses of the extruded alloys demonstrate excellent precision for the analytical method the high degree of analytical scatter for the cast metal suggests an effect of casting temperature. Although no direct relationship between casting temperatures and spectrographic analysis can be seen at this time, a trend toward higher iron values is noted up to $1350^{\circ} \mathrm{F}$. The considerably higher average standard deviation values at 1300 and $1350^{\circ} \mathrm{F}$. as compared to $1400^{\circ} \mathrm{F}$. warrant further investigation.

B. Purification Studies:

1. Vacuum Sublimation-Argon Casting Unit:

a. Summary of Operations:

The purification program using the previously described subliming and casting unit (see Biennial Report \#COO-85, this project, 1951) was continued during this quarter. A series of three sublimations and castings was completed using a graphite charge cradle and graphite entrainment barrier. The poor heat transfer of the graphite linings resulted in low yields (Table III), but $\delta$ lbs. of triply sublimed and cast magnesium was produced. 
b. Analysis of Purified Magnesium:

Spectrographic; chemical, and neutron activation analyses of the metal. produced in this series are listed in Table I under alloy numbers 67536,67537 , and 67538 (sve" runs 13, 14, and 15). The largest single impurity present is carbon, as shown by chemical analysis. In $67538,0.0107 \%$ of carbon was reported, probably introduced primari ly by the aoctylene black coating given the graphite lining to prevent sticking of the cast billet. This same lampblack treatment need not introduce more than $14 \mathrm{ppm}$ of carbon to the cast billet, however, when the billet is large enough to increase the ratio of $\mathrm{Mg}: \mathrm{C}$ as in alloy no. 67536.

The erratic nature of the carbon analyses indicates that carbon is somewhat segregated in the purified metal. Preliminary metallographic studies of 67538 bear out this observation.

Neutron activation analyses for iron in alloy numbers 67532, 67534, and 67535 were completed by the Spectroscopy Laboratory and are listed in the following table together with chemical and spectroscopic values. Neutron activation appears to be an excellent method for analyzing magnesium having extremely low iron contents. An ultimate sensitivity of a few hundredths of a part per million is indicated: No. of
Alloy No. Subl.Rec'd. Spect. Acid Wash ${ }^{1}$ Machined
Activation Fe ppm $67532 \mathrm{~B}$ $\mathrm{T}$

1

67534

67535

$C$
$D$
$E$
$F$
$G$
$H$
$I$

67536

67537

67538
18 20

12.6

1.0

9
1
4 $\quad$ in 7

$$
"
$$

$"$

i1

8

18
Activation

$7.08 \frac{ \pm 1}{10} 1.4 \%$

$0.90 \pm 1.9 \%$

$1.431 .7 \%$

$3.2 \quad 7.4$

1.6

2.6

1. Samples parted with hacksaw and acid washed.

Abbreviation for "Sublimation-Vacuum Casting" 
An examination of the above analyses shows that in every case. the spectrographic analyses are considerably higher than the chemical and neutron activation analyses. Since spectrographic results are standardied initially against chemical analyses, it would seem advisable to accept the chemical results as being more nearly correct. In the instances where both the chemical and neutron sotivation analyses are uvallable, it is considered that an average of the two results is the best value. The agreement between these latter two methods is seen to be quite good, particularly at the low values.

With reference to the preceding table, it is concluded that the iron impurity in magnesium can be reduced to $I$ part per miliion by the process of multiple sublimation and casting. It is interesting to observe that no further purification with respect to iron is obtained after the second sublimation and casting. It may be that iron leached from the graphite lining (which itself contains.3-.5\% iron) introduces this degree of contamination.

The spectroscopy Laboratory is cooperating in trying to determine the cause of the discrepancy between the methods of analysis. The results of their investigation will be reported at a later date.

\section{c. Cooling Rate of sVC Metal:}

Because of the known effect of thermal history on the corrosion rate of magnesium and its alloys, a typical cooling curve of the sublimed and cast billets (SVC-7 through SVC-15) is included (Fig. 24). It is seen that the well insulated vacuum furnace results in an extremely slow cooling rate.

d. Observed Corrosion Rates of High-Purlty Magnesium: The corrosion rates of various sublimed and cast magnesium samples are given in the following table together with the concentrations of critical impurities ${ }^{1}$ :

$I$ see also page 14 for discussion of $\mathrm{Fe}$ analyses. 


\begin{tabular}{|c|c|c|c|c|c|c|}
\hline \multirow[b]{2}{*}{ Alloy } & \multirow[b]{2}{*}{$\begin{array}{l}\text { Subl. } \\
\text { Rec'd. }\end{array}$} & \multicolumn{3}{|c|}{ Analyses ppm } & \multirow{2}{*}{$\begin{array}{l}\text { Corrosion } \\
\text { Rate, med }\end{array}$} & \multirow{2}{*}{$\begin{array}{l}\text { Exposure } \\
\text { Time } \\
\text { (aays) }\end{array}$} \\
\hline & & $\mathrm{Fe}$ & $M_{n}(a)$ & $c^{(c)}$ & & \\
\hline 67530 & $?_{11}^{2}$ & 5 (a) & 2 & ${ }_{n}^{29}$ & $\begin{array}{l}.26 \\
.28\end{array}$ & $\begin{array}{l}14 \\
14\end{array}$ \\
\hline 67531 & 4 & 11 (a) & $"$ & 24 & .33 & 7 \\
\hline 67532 & 1 & $9.8^{(b)}$ & 18 & 13 & .87 & 14 \\
\hline 67533 & $\begin{array}{l}4 \\
11\end{array}$ & & $?$ & 36 & $\begin{array}{r}.34 \\
.20\end{array}$ & $\begin{array}{l}14 \\
14\end{array}$ \\
\hline 67534 & 2 & $.95^{(b)}$ & 2 & 38 & .32 & 14 \\
\hline 67535 & 3 & $1.6^{(\mathrm{b})}$ & 1 & 20 & .32 & 14 \\
\hline 67536 & 1 & & 7 & 14 & .34 & 14 \\
\hline 67537 & 2 & $1.2^{(c)}$ & 3 & $80 \pm$ & .28 & 14 \\
\hline
\end{tabular}

(a) Spectrographic results

(b) Average of neutron activation and chemical results (c) Chemical results

Alternate immersion, $3 \% \mathrm{NaCl}$, average of 3 samples.

It can be seen that there is no apparent correlation between the amount of impurity and the observed corrosion rate (with the exception of "high" iron in 67532). However, due to possible segregation of impurities in the cast billet, analyses might not represent impurity content in corrosion specimens. Therefore, without care in sampling, correlation of analyzed impurity content with corrosion rate might lead to erroneous conclusions. Certain SVC billets (67532, 67533, and 67535) were rather thoroughly analyzed, and the results show that this possibility cannot be overlooked (see Table I, Biennlal Report \#c00-85, this project). Examination of the preceding table also shows that the more highly purlfled samples have no better corrosion rates, generally, than singly-sublimed materlal which has been melted with flux in graphite crucibles. It appears that there are several physical factors heretofore overlooked which may be affecting the corrosion rate of magneslum, but which are masked in materials having reasonably high corrosion rates. As the purity of the metal is increased to where the effect of cathodic impurity on the corrom sion rate is slight, it is conceivable that these other effects may 


\section{$-17-22000-88$}

become noticeable. Several such factors are listed below together with a briéf discussion of their possible influence on corrosion rate:

(1) Varying thermal history:

It has been shown that the corrosion rate is influenced by the thermal history of the material. This is primarily aue to the preclpltation or solution of a cathodic second phase, however, and as such, is directly related to the impurity content. There is the possibility that even in highpurity magnesium, varying thermal treatments may alter the corrosion rate. Rapid cooling might introduce residual internal stresses giving rise to stress induced corrosion. Annealing would be expected to relieve any such residual stresses and result in lower corrosion rates.

(2) Varying amounts of cold working:

In the preparation of corrosion specimens (machining, grinding, etc.), the specimen is subjected to a certain amount of cold working. The resultant surface stresses could'conceivably affect the corrosion rate adversely. This, indeed, is indicated by an examination of-corrosion patterns on high-purity magnesium. There is a definite tendency for corrosion to follow the direction of machining on the specimens.

(3) Surface contamination:

During specimen preparation, surface impurities may be introduced in amounts sufficient to initiate electrochemical attack.

(4) Surface roughness:

Due to the phenomenon of crevice corrosion which magnesium exhibits, surface roughness may play an important role in the corrosion rate of high-purity magnesium when the specimens are prepared by certain methods such as grinding or machining. Also, since corrosion rates are given in weight loss per unit area per unit time, it is important that the surface area be correctly known. It is reasonable to assume that.... if we consider two specimens of the same exterior dimensions, but having varying smoothness, the rougher specimen will have a larger actual 
surface area by virtue of its roughness. This should be considered in comparing corrosion rates of high-purity samples having varying surface preparations.

(5) Varying solution potentials and hydrogen overvoltages in different crystallographic directions:

Even if other effects could be completely eliminated, one must consider the posslulilty that the solution potential and hydrogen overvoltage might be different for one crystal face than for another. This could allow a local cell type of corrosion to occur in the absence of impurity.

It seems likely that all of these factors must be considered in the salt water corrosion of high-purity magnesium. At this point in the program, it would seem advisable to investigate the relative magnitudes of the above factors in order to determine the necessity for further purification studies. We may have reached a degree of purity where further removal of impurities has such a slight effect on corrosion rate as to be negligible in comparison with these other factors.

One interesting observation is that Alloy No. 67532, with approximately $10 \mathrm{ppm}$ of iron, has the fairly high corrosion rate of 0.9 mcd. This is quite evidently caused by impurity since the specimens pit appreciably on 14 day test. It is concluded that slow cooling (Fig. 24) can cause as little as 10 ppm of iron to affect the corrosion rate of magnesium. This indicates an extremely low solid solubility of iron in magnesium at low aging temperatures.

2. Tantalum-Lined Purification Unit:

In order to eliminate the last major source of contamination, namely carbon, the feasibility of operating a small, tantalum-lined sublimation and casting unit is being considered. Tantalum is known to have a very low solubility in molten magnesium" and should be an excellent liner material for a purification unit. Two disadvantages in constructing such a unit would be the high cost involved, and the fact that magnesium bonds to tantalum making removal of the solidified magnesium from the unit

Met. Lab. Report No. 11699, File No. 151 


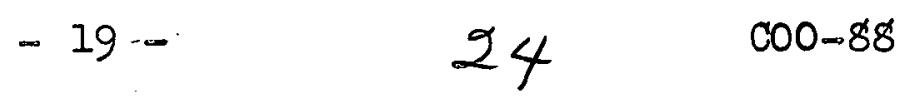

difficult. These disadvantages might be overcome by lining the casting crucible with a thin tantalum foll inexpensive. enough to be thrown away. The foil could be machined off of the purified magnesium after removing the solidified melt from the unit.

3. Arc-Melting of Sublimed Magn esium:

In order to provide a means of remelting high-purity sublimed magnodium without cruclule contamination, as-sublimed magnesium was arc-melted using the pure metal for both the electrode and hearth.

a. Apparatus and Procedure:

A diagram of the melting pot used for this serieg of experiments is given in Figure 23. A hearth of triply sublimed magnesium (69629-1) was sawed out of as-sublimed material and placed in the grounded melting pot. An electrode (approximately $3 / 4^{\prime \prime} \times 3 / 4^{\prime \prime} \times 12^{\prime \prime}$ ) was broken from the as-sublimed metal with as little handling as possible. Argon gas was introduced at an appreciable rate through the two small inlet tubes at the bottom of the melting pot to provide a protective atmosphere for melting. Then, using a standard Lincoln arc-welding machine, a pudale of magnesium 1 to 2 inches in diameter and $1 / 2$ inches thick was arc-melted on the hearth. clouding of the sight glass by vaporized magnesium was prevented by the argon entering adjacent to the sight glass. one problem encountered in the above procedure was the difficulty in maintaining an arc, because the electrode melted and dropped off in large drops. With currents up to 300 amperes and using reverse polarity, however, it was possible with practice to obtain melts of the above-mentioned size.

b. Analysis Results:

of the metallic impurities spectrographically

analyzed for (69629-2, Table I), only iron and manganese were detected. In view of the discrepancies discovered between the spectrographic, neutron activation, and chemical analyses of SVC magnesium (see page 14), the analysis results for 69629-2 may be somewhat high. The amount of iron present will be checked chemically to see if there is actually $12 \mathrm{ppm}$ of iron present. It is entirely possible, however, that the observed impurities were introduced during the handing prior to arcmelting. 


\section{c. Metallographic Examination:}

A metallographic examination was made of the triply sublimed and arc-melted magnesium (Alloy Nos. 69629-2, -3, -4). Figure 25 shows that the metal is quite clean except for a few rather irregular inclusions. These are probably magnesium oxide particles formed when the sublimed crystals are exposed to the. atmosphere before the arc-melting step.

\section{d. Corrosion Results:}

Fourteen-day corrosion rates were obtained on. the arc-melted metal with the following results:

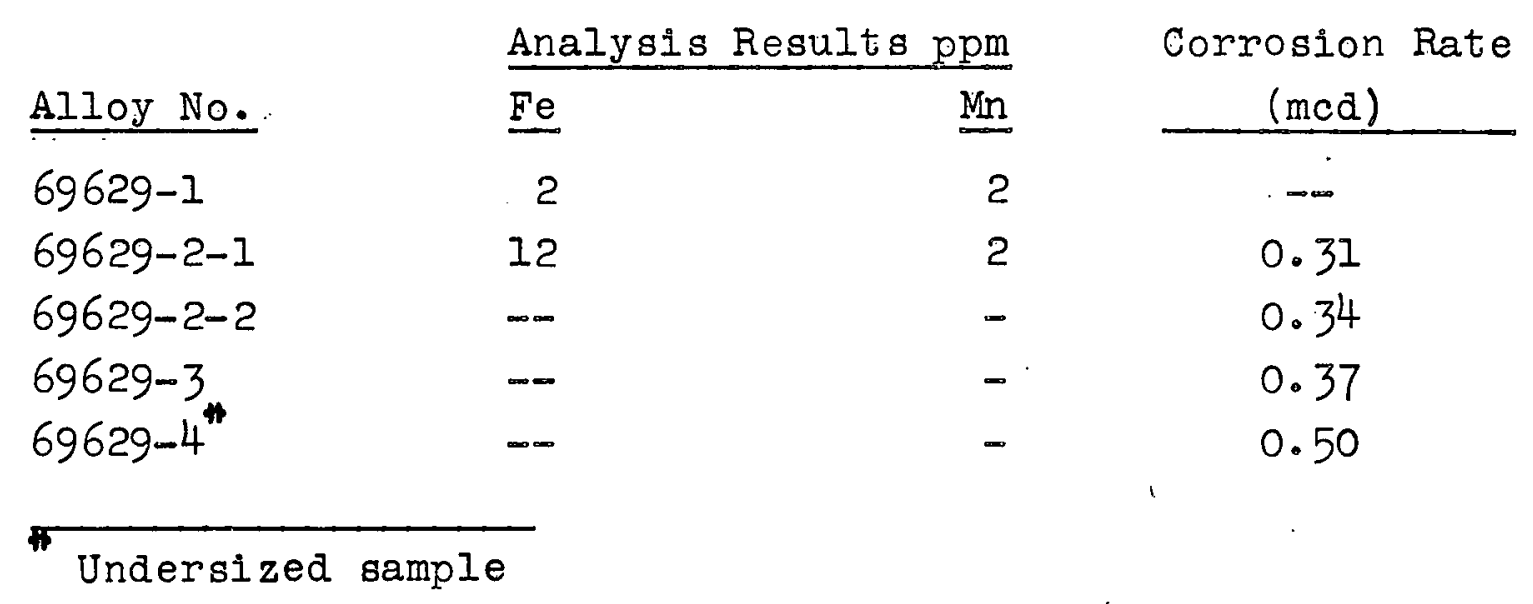

It is seen that the observed corrosion rates are no lower than those of ordinary singly-sublimed magnesium remelted with flux in graphite. This may be attributed to the apparent contamination by the iron. If it is shown chemically that iron isn't present in these amounts, however, the significance of the discussion on the corrosion of SVC magnesium may well apply here (page 17).

\section{REFERENCE:}

1 Hanawalt, Nelson, and Peloubet, T.P. No. 1353-E 353, A.I.M.E., September 1941. 
TABLS I

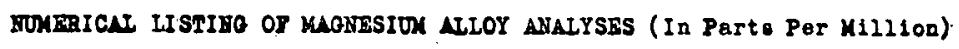

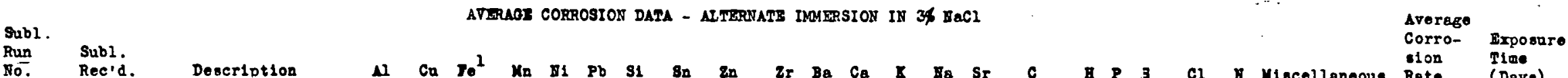

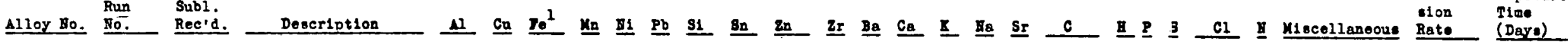

Sublimed Megnesium

67530 SVC-7

67531 SvC-8

67532 SVC-9

67533 SVC-10

67535 SVC-11

67536 SVC-13

$\begin{array}{lr}67537 & \text { SVC-14 } \\ 67538 & \text { STC-15 }\end{array}$
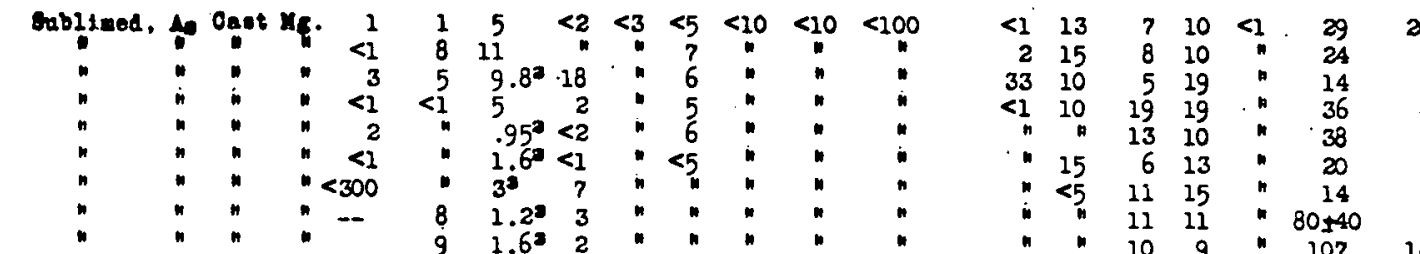

\begin{tabular}{|c|c|c|}
\hline & & $L_{1}=<25$ \\
\hline & 5 & $\begin{array}{l}B=<1 \\
B=<1\end{array}$ \\
\hline & 3 & $C_{r}=<1$ \\
\hline
\end{tabular}

$\begin{array}{rr}.26 & 14 \\ .33 & 7 \\ .87 & 14 \\ .34-.20 & 14 \\ .32 & 14 \\ .32 & 14 \\ .34 & 14 \\ .28 & 14\end{array}$

$\begin{array}{ll}68859 & s-61 \\ 59629-1 & 5-68 \\ 69629-2 & 3-68 \\ 59530 & 5-69\end{array}$

Sublimed $\mathrm{M}_{\mathrm{B}}$

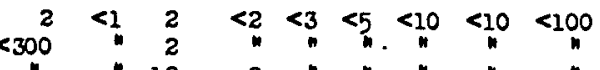

$<\begin{array}{lllll}10 & 11 & 27 & <1\end{array}$

ME-Fe Alloys

70655 467515 only (Mg - 370 ppm Fe)

$70656 \quad 467515+\$ 68859$ (sublimed $\mathrm{Mg}$ )

$70657 \quad \$ 67515+\$ 68859$

70658

70659

70650

705E1

70662

70663

70664

70665

70666

$\$ 68859$ only

70667

$\$ 67515+\$ 68859$

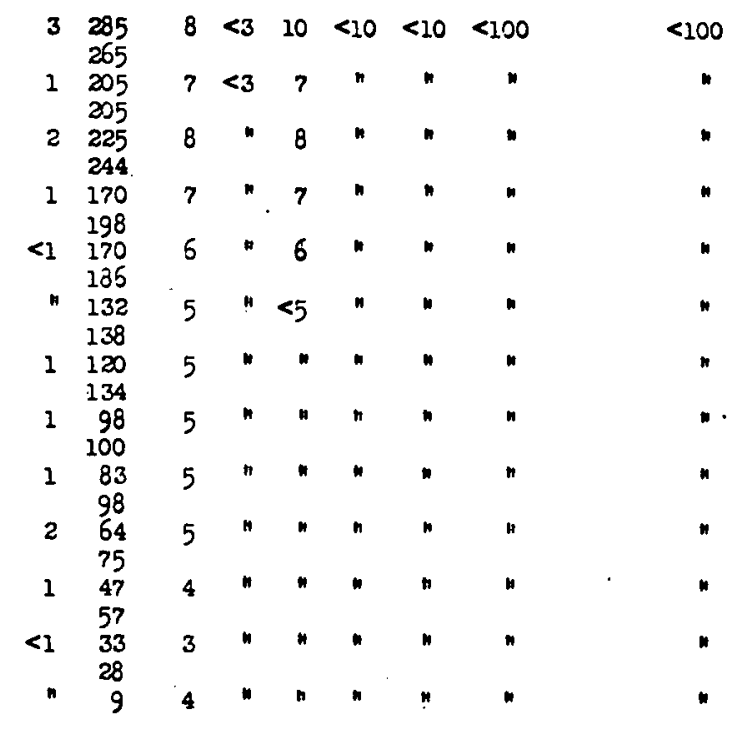


TABLE I (2)

Average

Corro- sxposure Time

Alloy 80. Descriotion

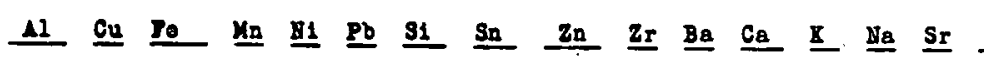
C E $\underline{\underline{P}} \underline{\mathrm{S}} \underline{\mathrm{Cl}}$ M1scellaneous Rate (Dayo)

\section{Mg-Jo Allore}

70668 . $\$ 67515+\$ 68859$

70669

20670

70671

70673

159313 only ( $\mathrm{HF}_{\mathrm{F}}-450$ pọm $\left.\mathrm{Te}\right)$

70674

158859 only

\section{Mg-Fe Master Alloye}

$70381+68859+\$ 67513$

70382

70383

70384

Mg-Fe-C Series

$70385 \quad 70381+3$ ens lampleck

$70386 "+70385$

$70387 \quad+\$ 70386$

$70388 \quad$ \$70381 onig (blank)

\begin{tabular}{|c|c|}
\hline 70390 & \$70 382 only (blank) \\
\hline 20391 & " + 3 gma lempblack \\
\hline 70392 & $\therefore+\$ 70391$ \\
\hline 70393 & $n+170392$ \\
\hline 70394 & $"+170393$ \\
\hline
\end{tabular}

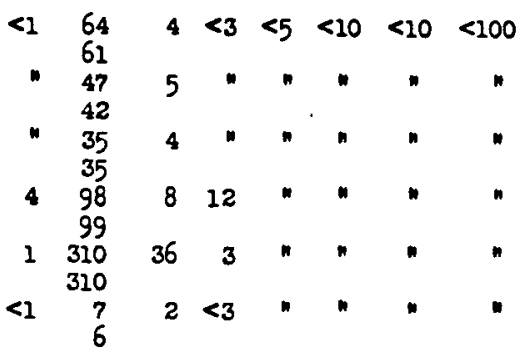

$<1 \quad 21 \quad 7<3<5<10<10<100$

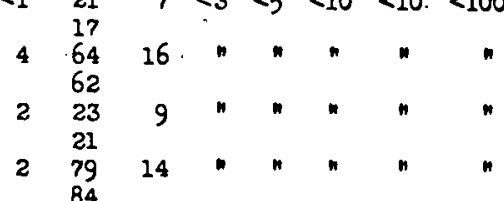

$1 \quad 17 \quad 7<3<5<10<10<100$

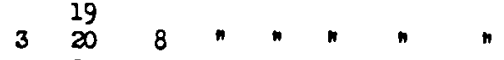

2 23

22

$1 \quad 22$

$\frac{18}{20}$

$\frac{18}{20}$ Ave.

$3 \quad 66 \quad 17<3<5<10<10<100$

26418 " ". " "

$3 \quad 6216$ " " " "

$2 \quad 6916$ " " " " "

$2 \begin{array}{llllll}57 & & & & & \\ 2 & 64 & 18 & & & \end{array}$

$\frac{97}{66}$ Avo
131
149
98
116
$<10$
212
29
39

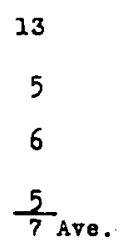

$\begin{array}{cc}1.71 & 1 / 8 \\ .378 & 7 \\ .995 & 1 / 8 \\ .385 & 7 \\ 1.03 & 1 / 8 \\ .366 & 7 \\ 1.03 & 1 / 8 \\ .312 & 7\end{array}$

88-32

$24-46$

28-59

14-118

$7-80$
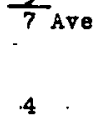

3

2

$j$

$\frac{15}{10}$ Ave.

$\begin{array}{cc}.868 & 1 / 8 \\ .477 & 7 \\ 2.864 & 1 / 8 \\ 7.07 & 7 \\ 10-29 & 1 / 8 \\ .723 & 7 \\ 3.65 & 1 / 8 \\ .642 & 7 \\ .8-7.6 & 1 / 8 \\ 1.30 & 7\end{array}$




\section{8}

TLBLP I (3)

Avorago

Corro- Expover

1on Ime

Alloy No. Description

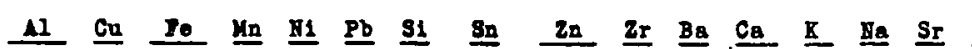

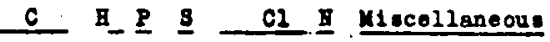

\begin{tabular}{|c|c|c|}
\hline 70398 & 168859 & only (blank) \\
\hline 70399 & 168859 & + 3 lampblack \\
\hline 70400 & & $+\$ 70399$ \\
\hline 70401 & & +770400 \\
\hline 70402 & $"$ & $+\$ 70401$ \\
\hline
\end{tabular}

\section{Me-Fe-Si Series}

$\begin{array}{lc}70433 & \$ 0383 \text { only (blank) } \\ 70434 & \$ 70383+0.7 \text { gme S1 } \\ 70435 & +\$ 0434 \\ 70436 & "+\$ 70435 \\ 70437 & "+70436 \\ 70438 & \$ 70384 \text { only (blank) } \\ 70439 & \$ 70384+0.7 \text { gms s1 } \\ 70440 & "+\$ 70439 \\ 70441 & "+\$ 70440 \\ 70442 & m+\$ 70441\end{array}$

Mg-Fe Mester Alloys

$70468 \quad 168859+167515$

70469

70470

70471

${ }^{1}$ Unlese Otherwl se Noted, results are spectrographic

2 Average of neutron ectivation end chemical analyses.

Chemical analysio.

9 Ave.

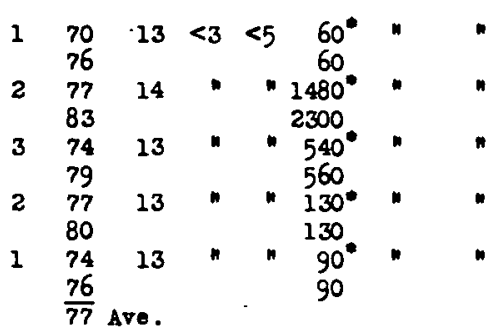

$\begin{array}{cc}59-148 & 76-483 \\ 21-25 & 6 \\ 16-39 & 12 \\ 13-37 & 14 \\ <10-50 & 19->140\end{array}$
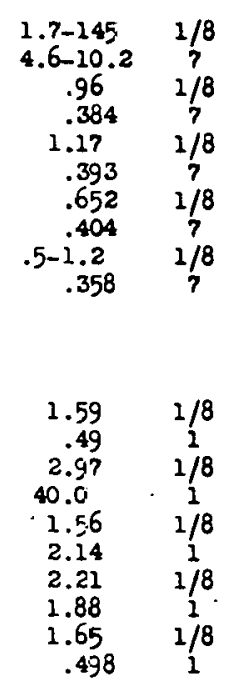

$\begin{array}{rc}162 & 1 / 8 \\ \text { Destroyed } & 1 \\ 24.4 & 1 / 8 \\ 172 & 1 \\ 85 & 1 / 8 \\ 114 & 1 \\ 125 & 1 / 8 \\ \text { Destroyod } & 1 \\ 137 & 1 / 8 \\ \text { Destroyod } & 1\end{array}$

- Single test. 


\section{TABIE II 9}

DETAILED CORROSION AND SOLUTION POTENTIAL DATA

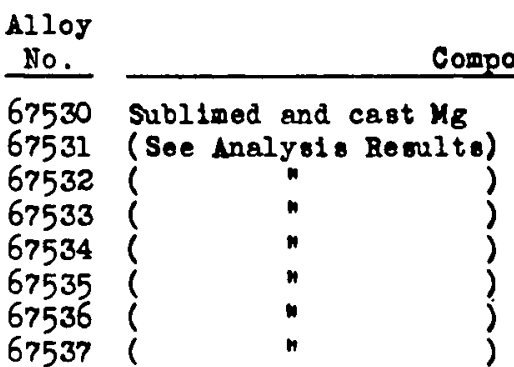

67929-2,3 3x sublimed and arc-melted $\mathrm{Mg}_{\mathrm{B}}$ $(\mathrm{Te}=12 \mathrm{ppm})$

\section{Mg-Fe-C Series}

$70385-1+17-19$ Fo -218 Ave.

-3
-4

$131-1490$

140 Ave.

70386-1 20-23 Ie

$-2 \quad 21$ Ave.

-3
-4

$70387-1 \quad 19-24$ Fe

$-2 \quad 21$ Are.

$-3$

70388-1 18-22 Fe

$-2 \quad 20$ Ave.

-3
-4

70390-1 62-66 Fe

-264 Are.

$-3$

$32-88 \mathrm{C}$

60 Ave. omposition (pom)

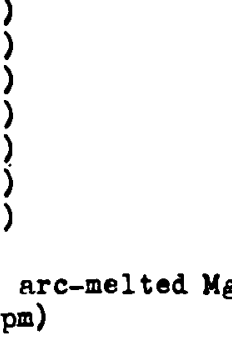

Molt Size Thermal History

25 lbe. Slow cool( IIg 24) $^{2}$

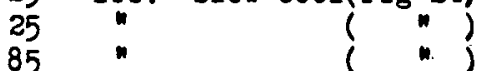

24

29

49

25.5

5-10 gos. Shock cooled
Solution

Potential

(Volts) $14^{\circ}$ day

.26

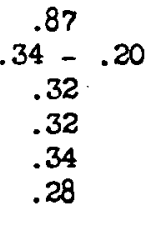

.34

Triolicate determinations

\begin{tabular}{|c|c|c|c|c|}
\hline $\begin{array}{l}135 \\
135 \\
135 \\
135\end{array}$ & $\begin{array}{c}\text { gm } 8 . \\
n " \\
n\end{array}$ & $800^{\circ} \mathrm{C}$ & $\begin{array}{l}1.56 \\
\frac{1.87}{1.71} \text { Ave. }\end{array}$ & $\begin{array}{r}.390 \\
.366 \\
738\end{array}$ \\
\hline
\end{tabular}

1.667

.667

1.665

1.666 Ave.

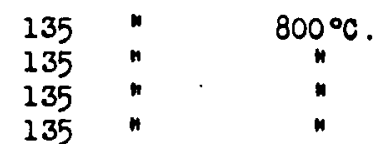

$\begin{array}{r}.993 \\ .998 \\ \hline .995\end{array}$

$\frac{.998}{.995}$ Ave

378 rve

1.667

1.666

1.672

1.668 Ave.

55 Are.

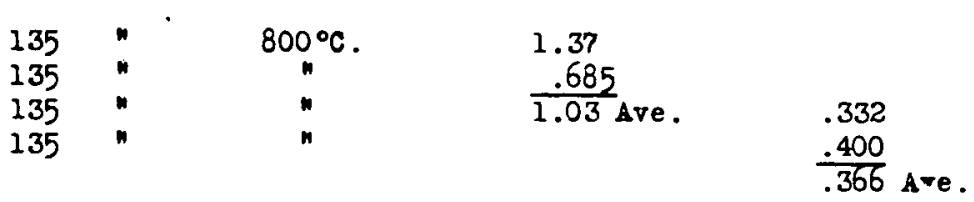

1.668

1.668

1.666

$\frac{1.666}{1.667 \text { Ave. }}$

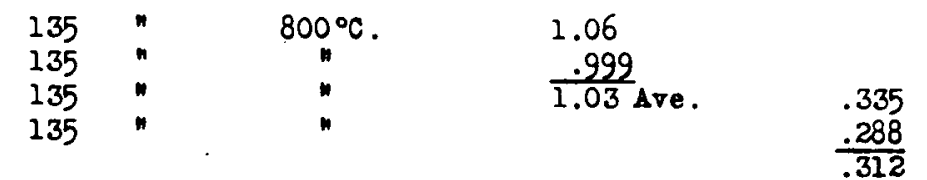

1.666

1.667

1.665

1.666 Ave.

$\begin{array}{cc}135 & " \\ 135 & 800^{\circ} \mathrm{C} . \\ 135 & " \\ 135 & "\end{array}$

.686

$\frac{1.25}{.858}$
1.661

1.661

$\frac{1.661}{1.661}$ Ave. 
$\Delta 1108$

No.

70391-1.64-64 Fe

64 ive.

$-3$

20392-1 59-62 Je

$-260 \Delta v e$.

-3
-4

70393-1 57-68 $\mathrm{Fo}$

-262 Ave.

-3
-4

70394-1 64-97 Fo

-280 Are.

$-3$

Pure Mg-C Serteg

70398-1 7-7 7

-2 7 Ave.

-3
-4

$\begin{array}{rl}70399-1 & 7-10 \text { Fe } \\ -2 & 8 \Delta \nabla e \\ -3 & \\ -4 & \end{array}$

70400-1 12-18 Fe

-215 Ave.

-3
-4

70401-1 8-14 Fe

$\begin{array}{ll}-2 & \text { II } A \nabla 0 .\end{array}$

$-4$
Composition (ppm)

35

$29-59 \mathrm{C}$

43 Ave.

14-114 C

61 Ave.

7-80 C

43 Are.

103 Aro.

21-25 C

23 Are.

16-39 c

27 Are.

13-37 C

$25 \Delta$ ․․
SABL $\frac{30}{(2)}$

Altornate Immergion Corrosion Rate (med). Solution

\begin{tabular}{|c|c|c|c|}
\hline 3 hour & $\begin{array}{l}\text { Bxposure } \\
7 \text { day }\end{array}$ & $14 \mathrm{day}$ & $\begin{array}{l}\text { Potential } \\
\text { (Volte) }\end{array}$ \\
\hline 2.86 & $\begin{array}{r}4.17 \\
10.98 \\
7.07\end{array}$ & & $\begin{array}{l}1.657 \\
1.658 \\
1.654 \\
1.656\end{array}$ \\
\hline
\end{tabular}

\begin{tabular}{|c|c|c|}
\hline${ }^{800^{\circ} \mathrm{C} .}$ & $\frac{29.0}{10.1} \Delta \nabla 0$ & $\begin{array}{l}1.035 \\
\frac{.411}{.723} \text { Ave. }\end{array}$ \\
\hline
\end{tabular}

1.649

1.653

1.652

$\overline{1.651}$ Ave.

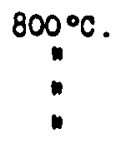

4.87

2.43

$\frac{2.43}{3.65}$ Ave.

.759
526

$\frac{.526}{.642}$ Aro

$1: 655$

1.655

$\frac{1.658}{1.656}$ Ave

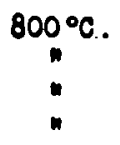

7.59

.880

Ave. $\quad 1.62$

1.62
.990

$\frac{.990}{1.30 \text { Ave. }}$

1.655

1.660

1.659

1.658 Ave.

1.668

1.670

1.668

4.59

1.669 Ave.

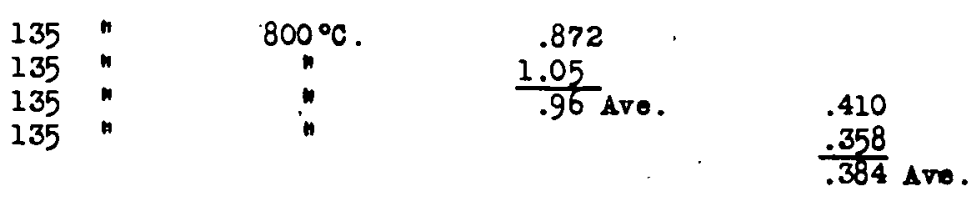

1.670

1.667

1.669

1.669 Ave.

135
135
135
135
135
135
135
135

$800^{\circ} \mathrm{C}$

1.30

$\frac{1.05}{1.17}$ Are.

1.669

1.669

1.669

$\overline{1.669}$ Ave.

$\frac{.373}{.393}$ Ave.

1.671

1.668

1.669

1.669 Are. 
Alloy
No.

20402

0402-1 5-6 Fe

$\begin{array}{ll}-2 & 5 \text { Ave. } \\ -3 & \end{array}$

-3
-4

\section{$\underline{\text { Mg-Fe-Si Series }}$}

70433-1 22-23 I

-2
-3

$-4$

\begin{tabular}{|c|c|c|c|}
\hline $\begin{array}{r}70434-1 \\
-2 \\
-3 \\
-4\end{array}$ & $22-25 \mathrm{Fe}$ & $1900 \mathrm{S1}$ & $1490 \mathrm{Si}$ \\
\hline $\begin{array}{r}70435-1 \\
-2 \\
-3 \\
-4\end{array}$ & $19-20 \mathrm{Fe}$ & $370 \mathrm{S1}$ & $490 \mathrm{Si}^{\circ}$ \\
\hline $\begin{array}{r}70436-1 \\
-2 \\
-3 \\
-4\end{array}$ & $19-22 \mathrm{Fe}$ & $210 \mathrm{~s} 1$ & $250 \mathrm{si}$ \\
\hline $\begin{array}{r}70437-1 \\
-2 \\
-3 \\
-4\end{array}$ & $22-26 \mathrm{Fe}$ & $140 \mathrm{~S} 1$ & $170 \mathrm{Si}$ \\
\hline $\begin{array}{r}70438-1 \\
-2 \\
-3 \\
-4\end{array}$ & 70-76 Fe & $60 \mathrm{s1}$ & $60 \mathrm{si}^{\circ}$ \\
\hline
\end{tabular}

Chemical analygis

$3 \mathrm{Si}^{*}$

$<1051$

.

31

TABLE II (3)

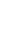

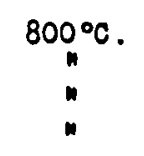

135
135

135

135 "

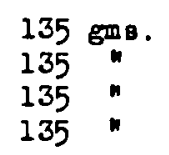

135 "
135
135
135

$135 "$
$135 "$
$135 "$
$135 "$
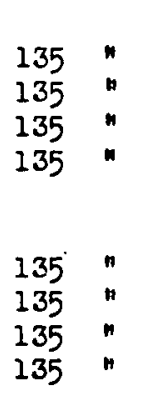

$135 " "$
$135 "$
$135 "$
135

$135 "$
135
$135 "$
135
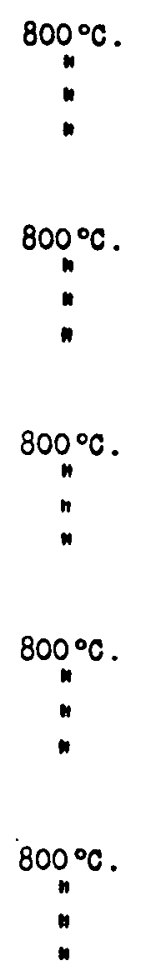

$800^{\circ} \mathrm{C}$

$800^{\circ} \mathrm{C}$.
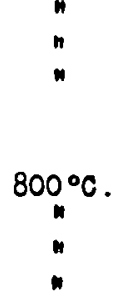

${ }^{800^{\circ} \mathrm{C} .}$

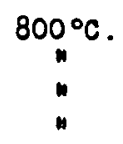

Alternate Immersion Corrolion Rate (med)

3 hour

Exposure

7 day

14 dar

Solution

Potential

.497

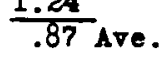

.380

$\frac{.337}{.358}$ Ave .

1 day

1.62

$\frac{1.50}{1.59}$ Ave.

$\begin{array}{r}.505 \\ .476 \\ \hline\end{array}$

$\frac{.476}{.490 \text { Ave. }}$

2.69

$\frac{3.26}{2.97}$ Ave

31.4

48.7

40.0 ATE.

1.37

$\frac{1.75}{1.56}$ Ave.

1.94

2.34

2.14 Are.

2.30

2.12

$\frac{2.12}{2.21}$ Ave.

2.53

1.24

1.88 Ave.

1.43
$\frac{1.87}{1.65 \text { Ave. }}$.

.467

.530

$\frac{.530}{.498}$ Are.

170
$\frac{155}{162}$ Ave.

1.662

1.661

1.661

1.661 Ave.

1.661

1.661

1.661

1.661 Ave.

1.662

1.662

1.663

1.662 Ave.

1.663

1.663

1.662

$\overline{1.663}$ Ave

1.663

1.663

1.663

1.663 Ave.

1.646

1.646

1.645

1.646 AVO. 


\section{2}

TABLS II (4)

$$
\begin{aligned}
& \text { Alloy } \\
& \text { No. }
\end{aligned}
$$

70439-1

$$
\begin{aligned}
& -2 \\
& -3 \\
& -4
\end{aligned}
$$

$\begin{array}{rl}70440-1 & 74-79 \mathrm{Pe} \\ -2 & \\ -3 & \\ -4 & \end{array}$

$\begin{array}{rl}70441-1 & 77-80 \mathrm{Fe} \\ -2 & \\ -3 & \\ -4 & \end{array}$

7.0442-I 74-76 $\mathrm{Pe}$

-2
-3
-4
Composition (pom)

$2300 \mathrm{s1}$

$1480 \mathrm{S1} *$

Meit S1ze

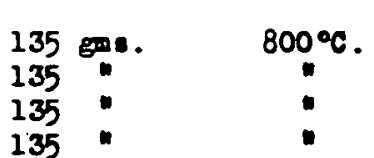

$560 \mathrm{si}$

$540 \mathrm{SI}^{\circ}$

$$
\begin{aligned}
& 135 " \\
& 135 \\
& 135 \\
& 135
\end{aligned}
$$

13051

$130 \mathrm{s1}$

$90 \mathrm{si}$

$90 \mathrm{si}^{*}$

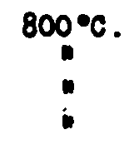

Alternete Immersion Corrocion Rate (med) Bxposure

3 hour

21.2

$\frac{27.6}{24.4}$ Are.

$$
\begin{aligned}
& 135 \\
& 135 \\
& 135 \\
& 135 \\
& 135 \\
& 135 \\
& 135 \\
& 135
\end{aligned}
$$

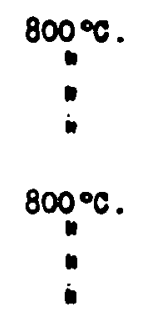

66.5

61.0 it Are

125

$\frac{124}{125}$

$\frac{124}{125}$ Are.

141.5

133.5

$\frac{138.5}{137}$ ATQ .

destroyed

destroyed

destroyed
$1 \mathrm{dey}$

257.7

190.0

$\frac{172.0}{172.0}$ Are.

Solution Potential.

(Voltu)

1.661

1.659

1.660

$\overline{1.660}$ Are

1.654
1.648

1.648
1.649

$\frac{1.649}{1.647} \Delta \mathrm{ve}$

1.649

1.651

1.652

destroyed
1.648

1.649

1.649

1.649. Ave . 


\section{3}

TABLI III

SUBLIMATION DATA AND OPERATING CONDITION8

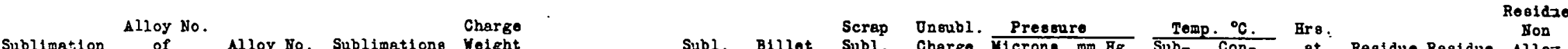

of Alloy No. Sublimations Wolght Charge Metal Wubl. Billot Subl.

STC-13

P1lter Remarik:

\begin{tabular}{|c|c|c|c|c|c|c|c|c|c|c|c|c|c|c|c|c|c|c|c|}
\hline SVC-13 & -- & 67536 & 1 & 69 & $P N-D C(69782)$ & - & 49 & 25 & 5 & 33 & $\begin{array}{l}.001- \\
.002\end{array}$ & 700 & $\begin{array}{l}300- \\
350 \\
\end{array}$ & 144 & 28 & .09 & 6396 & $\begin{array}{l}\text { Graphl te } \\
\text { Sieve } \\
\text { with } \\
\text { Graph1 te } \\
\text { Granule. }\end{array}$ & $\begin{array}{l}\text { Cast at } \\
825 \% . \\
\text { for } \\
5 \mathrm{hre} .\end{array}$ \\
\hline SVC-14 & -- & 67537 & 2 & 45 & 67536 & -- & 25.5 & 2 & 17.5 & $27-50$ & .002 & 700 & $\begin{array}{l}300- \\
340\end{array}$ & 71 & -- & -- & -- & $\begin{array}{l}\text { Oraphite } \\
\text { Slevo } \\
\text { w1th } \\
\text { Oraphite } \\
\text { Granules }\end{array}$ & $\begin{array}{l}\text { Cast a: } \\
825^{\circ} \mathrm{C} . \\
\text { for } \\
15 \mathrm{hrs} .\end{array}$ \\
\hline src-15 & -- & 67538 & 3 & 23 & 67537 & - & 8 & 9 & 6 & $22-23$ & .0007 & 675 & $\begin{array}{l}300- \\
325\end{array}$ & 76 & 1.7 & .02 & -- & $\begin{array}{l}\text { Graph1 to } \\
\text { Sieve } \\
\text { with } \\
\text { Graph1 to } \\
\text { Granulea }\end{array}$ & $\begin{array}{l}\text { Cast at } \\
825 \% \text {. } \\
\text { for } \\
15 \mathrm{hro} .\end{array}$ \\
\hline
\end{tabular}




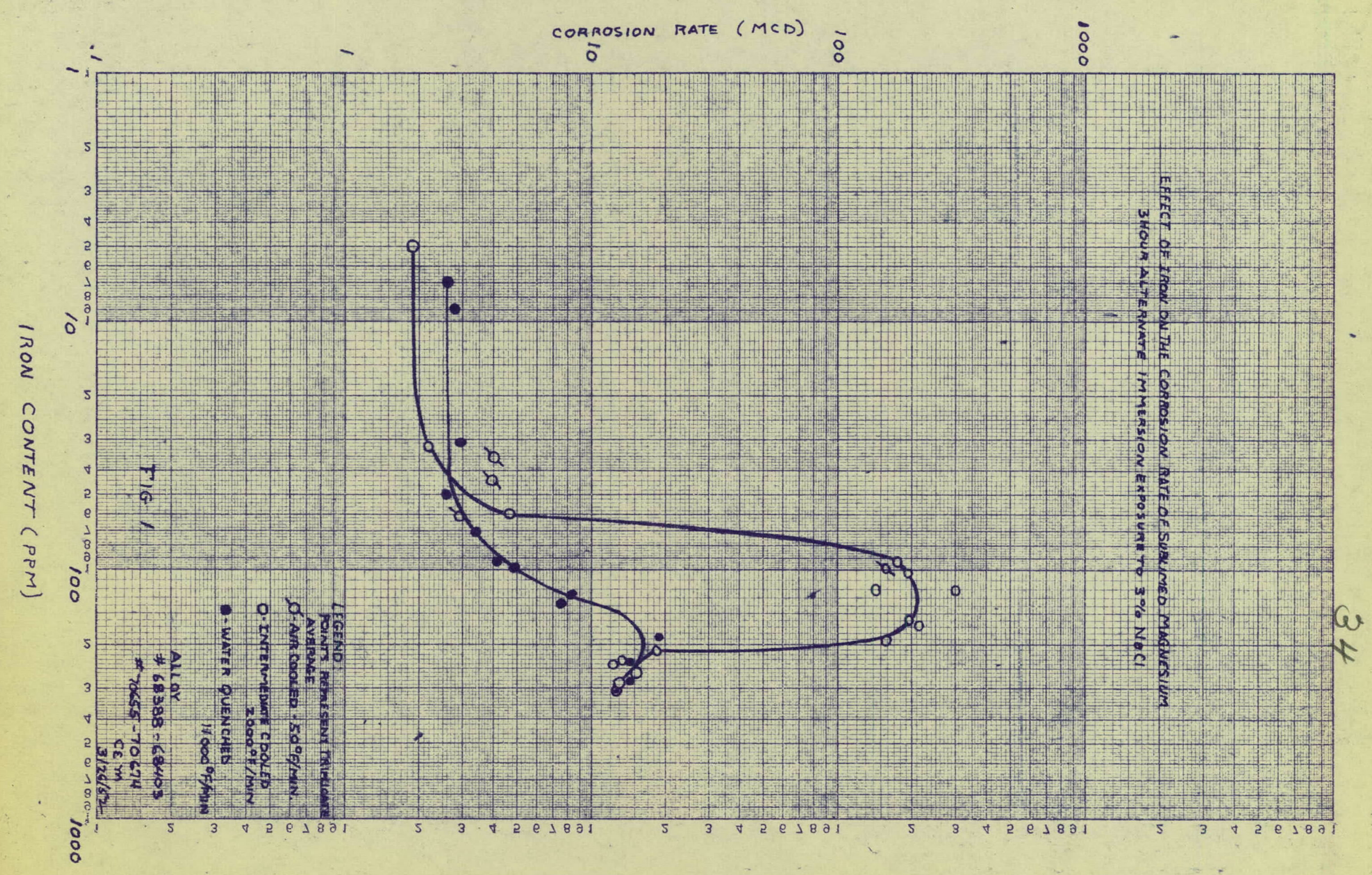




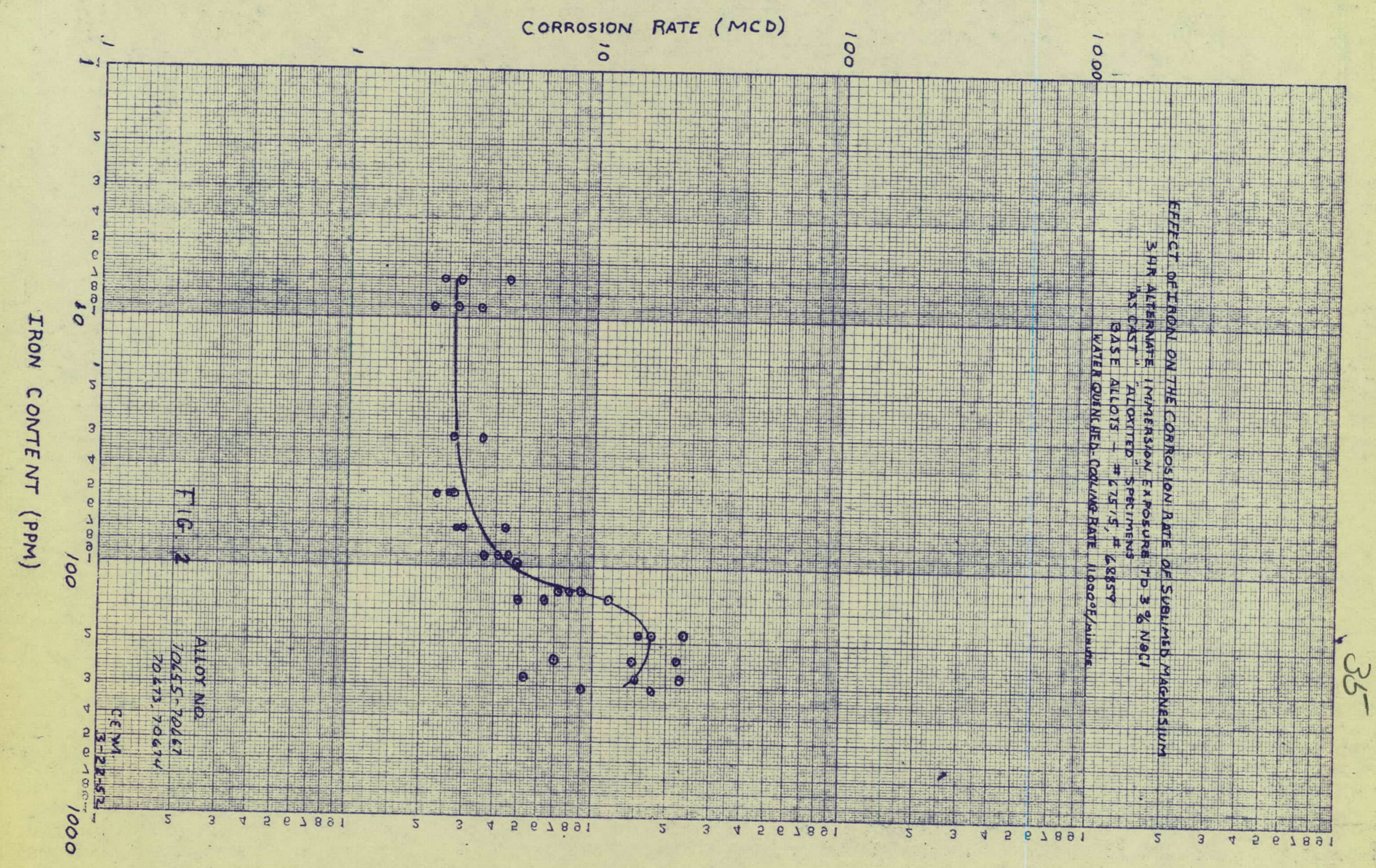




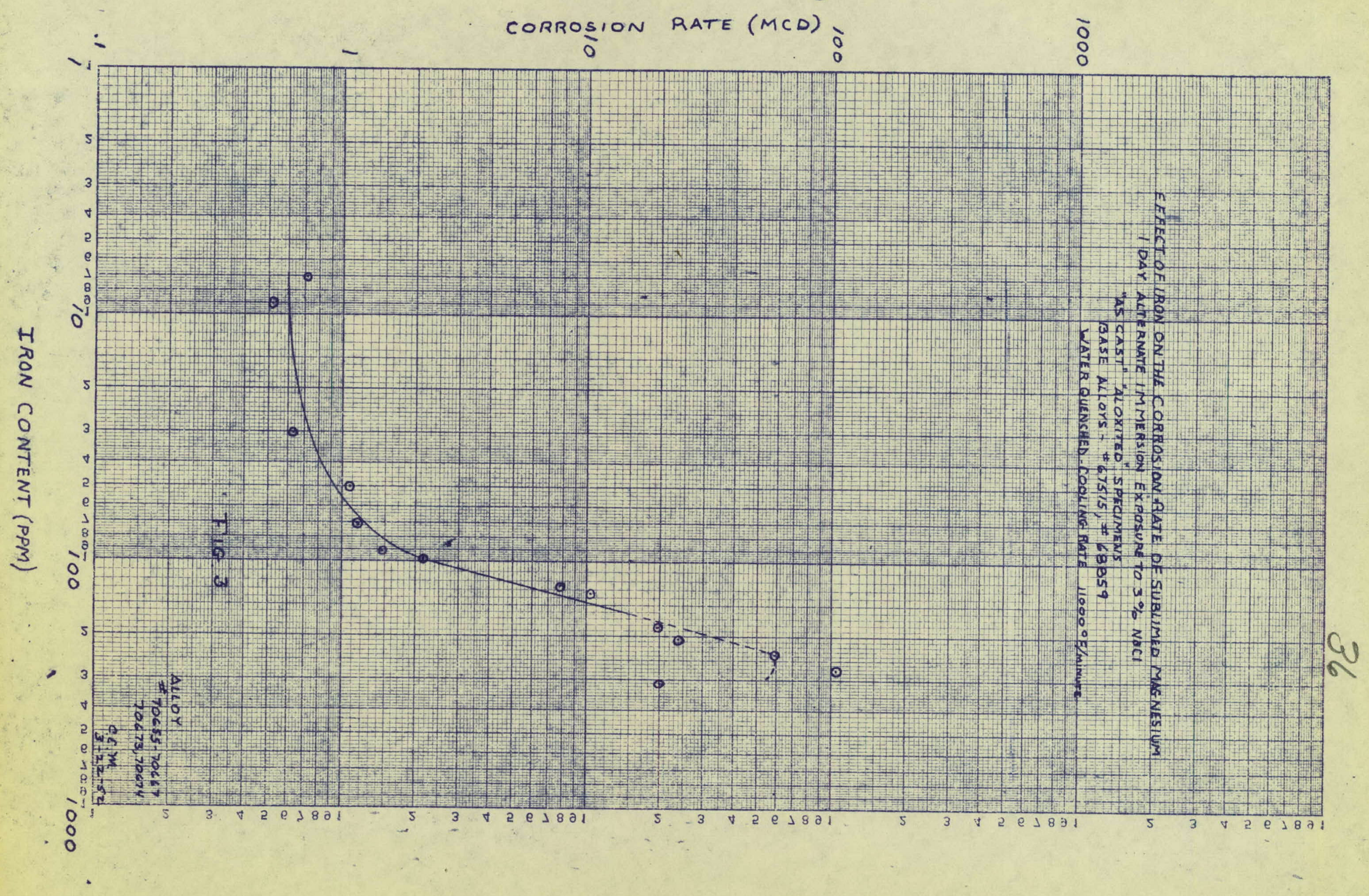

AVDE IUA'2.

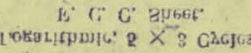




\section{MAGNESIUM-IRON CORROSION SPECIMENS \\ 3 HOUR AL TERNATE IMMERSION IN 3\% NaC}

COOLING RATE $11000^{\circ} \mathrm{F} /$ MINUTE

Alloy \#70661-70674

Iron Content PPM

31

52

70

2.8 MCD

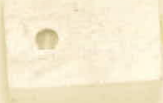

2. $74 \mathrm{MCD}$

(9)

3. $5 \mathrm{MCD}$

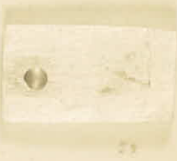

$2.3 \mathrm{MCD}$

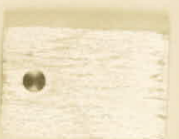

2.94 MCD

91

99

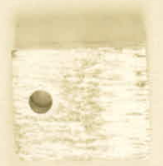

4. $93 \mathrm{MCD}$
4. $43 \mathrm{MCD}$

e.
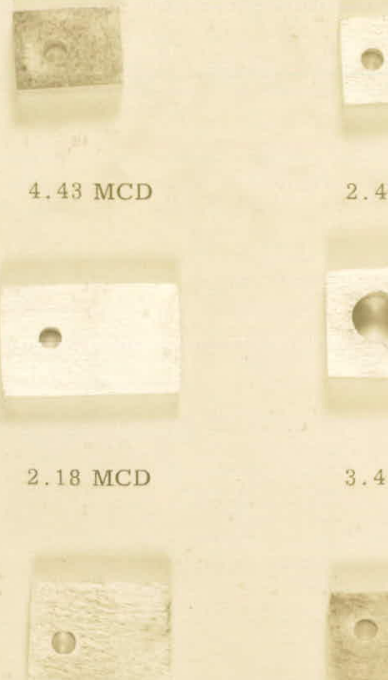

2. $4 \mathrm{MCD}$

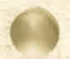

3. $4 \mathrm{MCD}$

2. $18 \mathrm{MCD}$

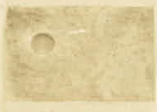

2. 7 MCD

2.7 MCD

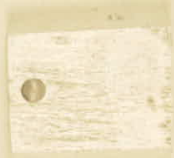

2.59 MCD

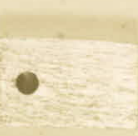

4. $43 \mathrm{MCD}$

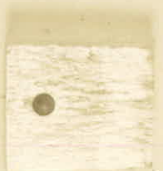

4. 58 MCD

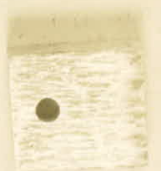

4.97 MCD
2.78 MCD

4. 01 MCD

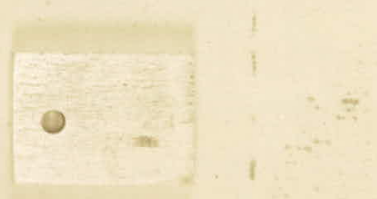

2. 74 MCD
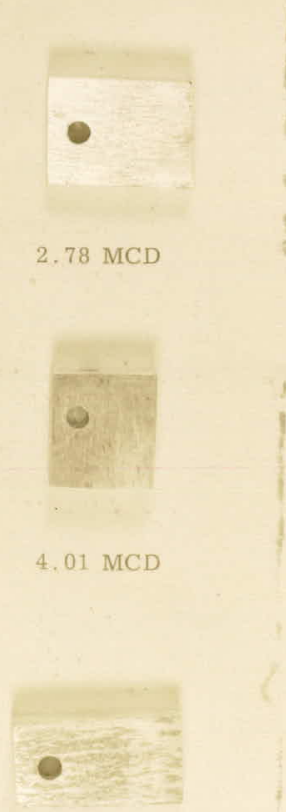

4. 91 MCD 
MAGNESIUM-IRON CORROSION SPECIMENS

3 HOUR ALTERNATE IMMERSION IN $3 \% \mathrm{NaCl}$ COOLING RATE $11000^{\circ} \mathrm{F} /$ MINUTE

Iron Content PPM

127

135

184

205

235

275

310
Alloy \#70661-70674

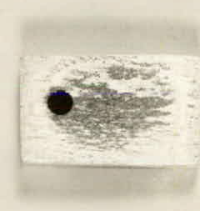

7.25 MCD

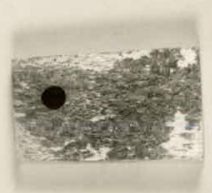

6.4 MCD

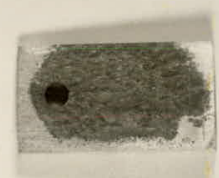

15. $47 \mathrm{MCD}$

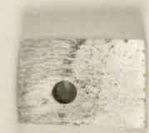

4.97 MCD

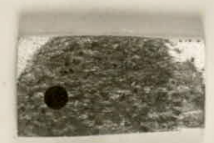

14.49 MCD

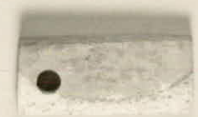

15.02 MCD

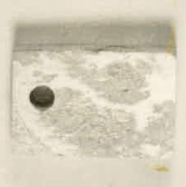

9.0 MCD

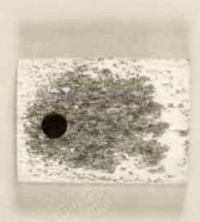

8. $95 \mathrm{MCD}$

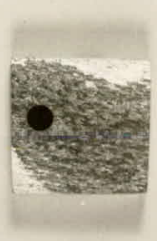

11. $3 \mathrm{MCD}$

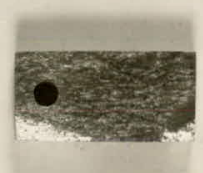

17.7 MCD

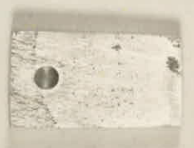

3. $29 \mathrm{MCD}$

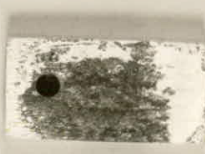

7.11 MCD

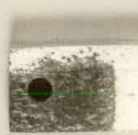

22. $45 \mathrm{MCD}$

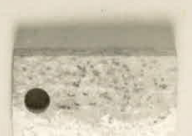

17. $3 \mathrm{MCD}$

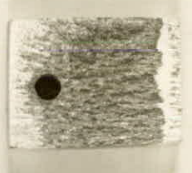

8.15 MCD

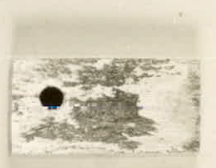

4. $93 \mathrm{MCD}$

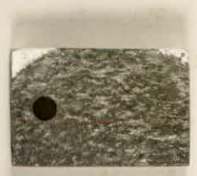

$23.6 \mathrm{MCD}$

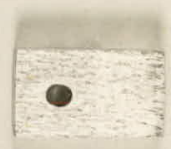

5. $3 \mathrm{MCD}$

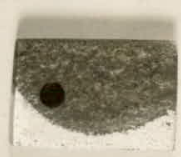

22.13 MCD

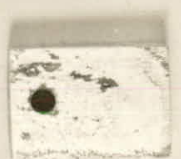

5. $35 \mathrm{MCD}$ 
MAGNESIUM-IRON CORROSION SPECIMENS

1 DAY ALTERNATE IMMERSION IN 3\% NaCl COOLING RATE $11000^{\circ} \mathrm{F} /$ MINUTE

Alloy \#70655 - 70674

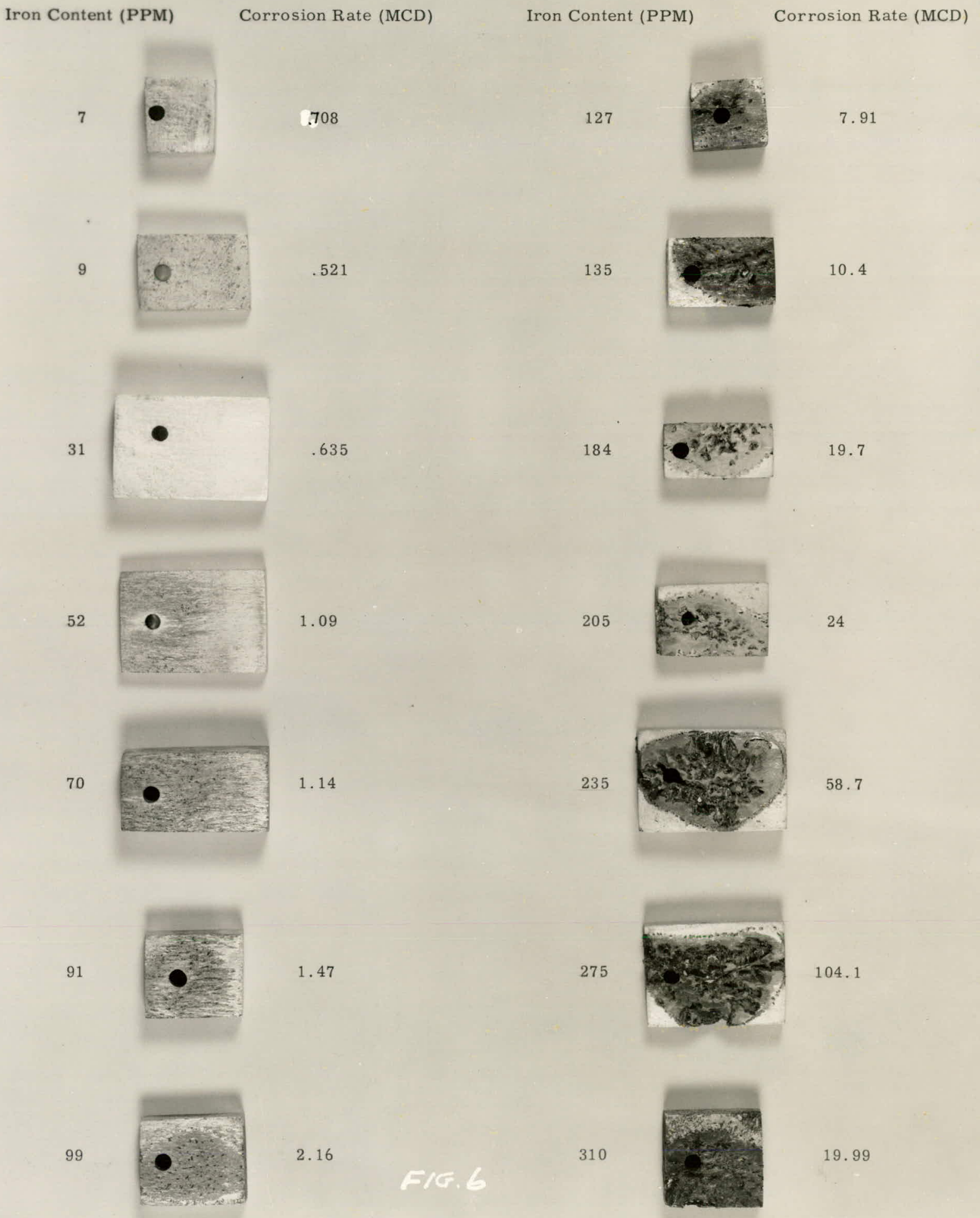


MAGNESIUM-IRON CORROSION SPECIMENS

ALTERNATE IMMERSION IN 3\% NaCl

99 PPM IRON

Alloy \#70662-70671

3 HOUR EXPOSURE

SLOW COOLED $\left(50^{\circ} \mathrm{F} / \mathrm{MINUTE}\right.$

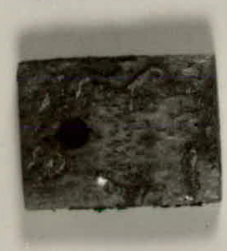

180.3 MCD

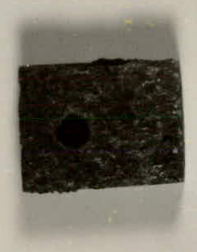

129.9 MCD

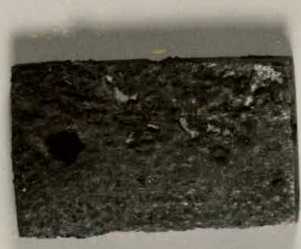

.

147.0 MCD
RAPIDLY COOLED $11000^{\circ} \mathrm{F} /$ MINUTE

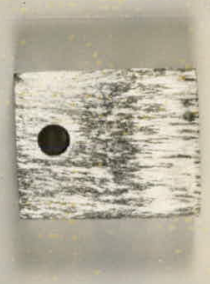

4. $93 \mathrm{MCD}$

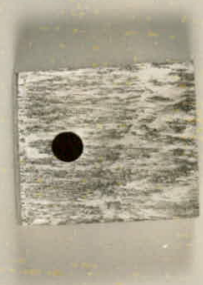

4. $97 \mathrm{MCD}$

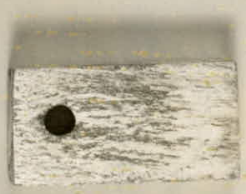

4. $91 \mathrm{MCD}$

1 DAY EXPOSURE

\section{F/a. 7}

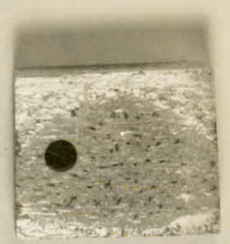




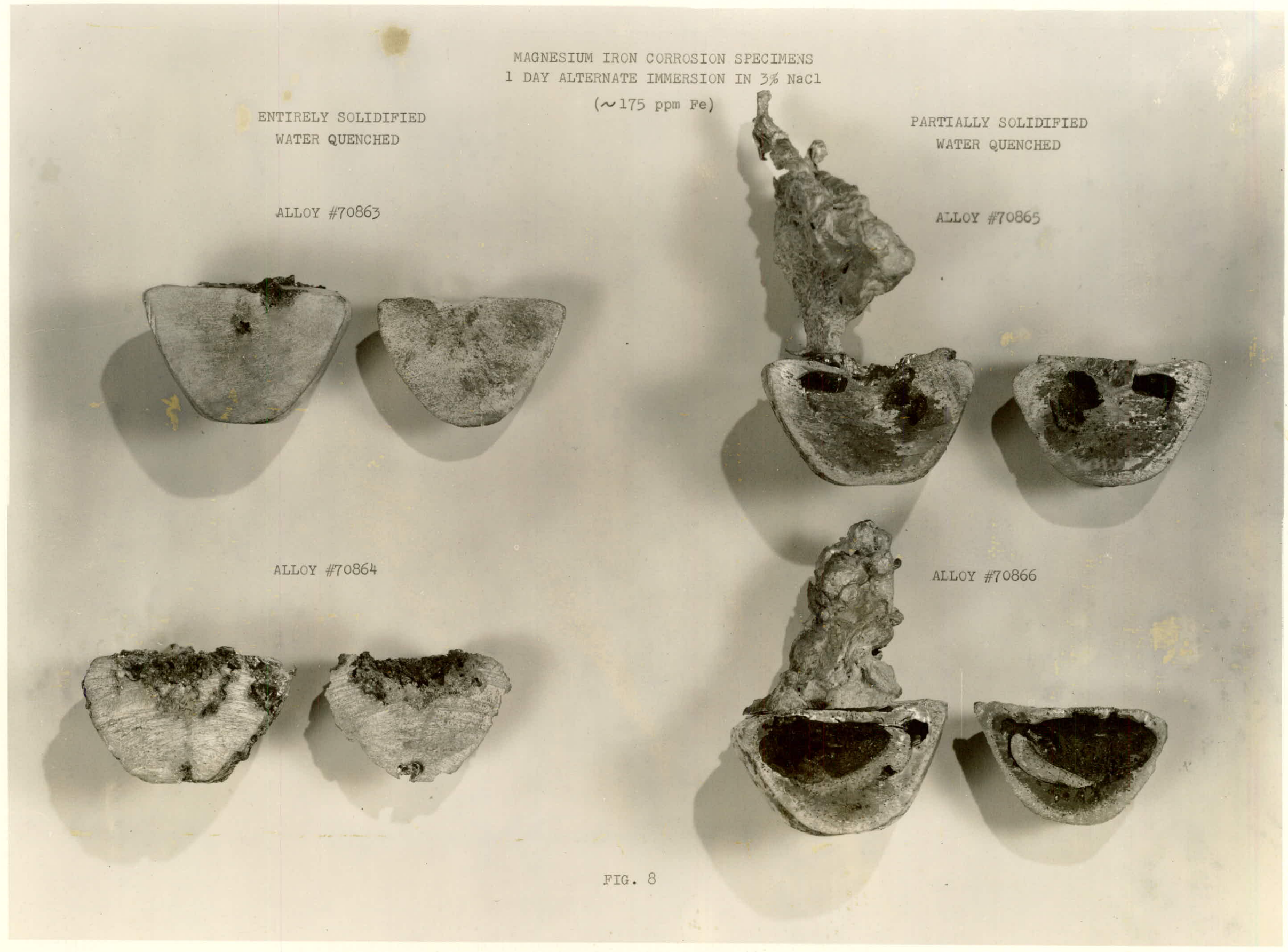




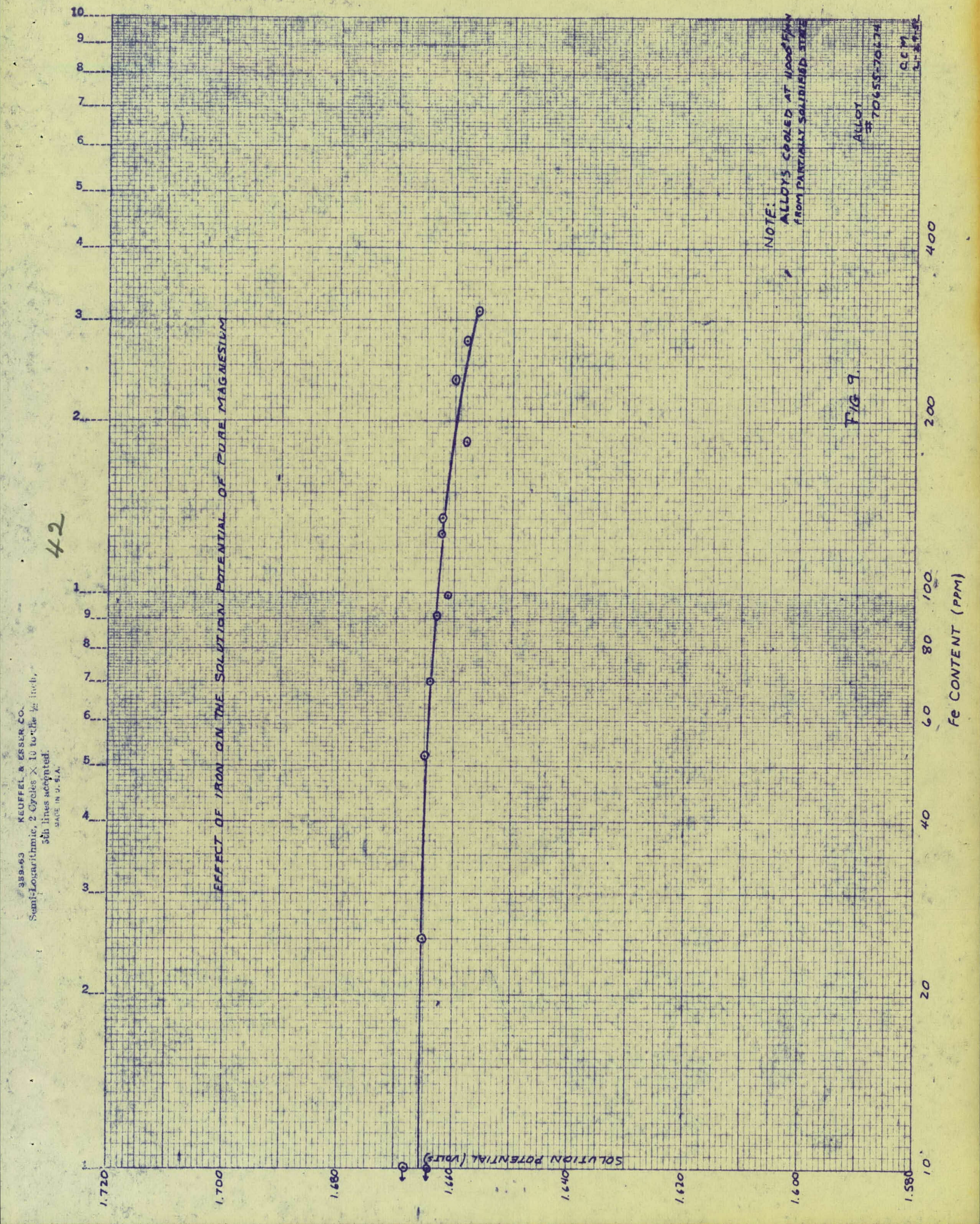




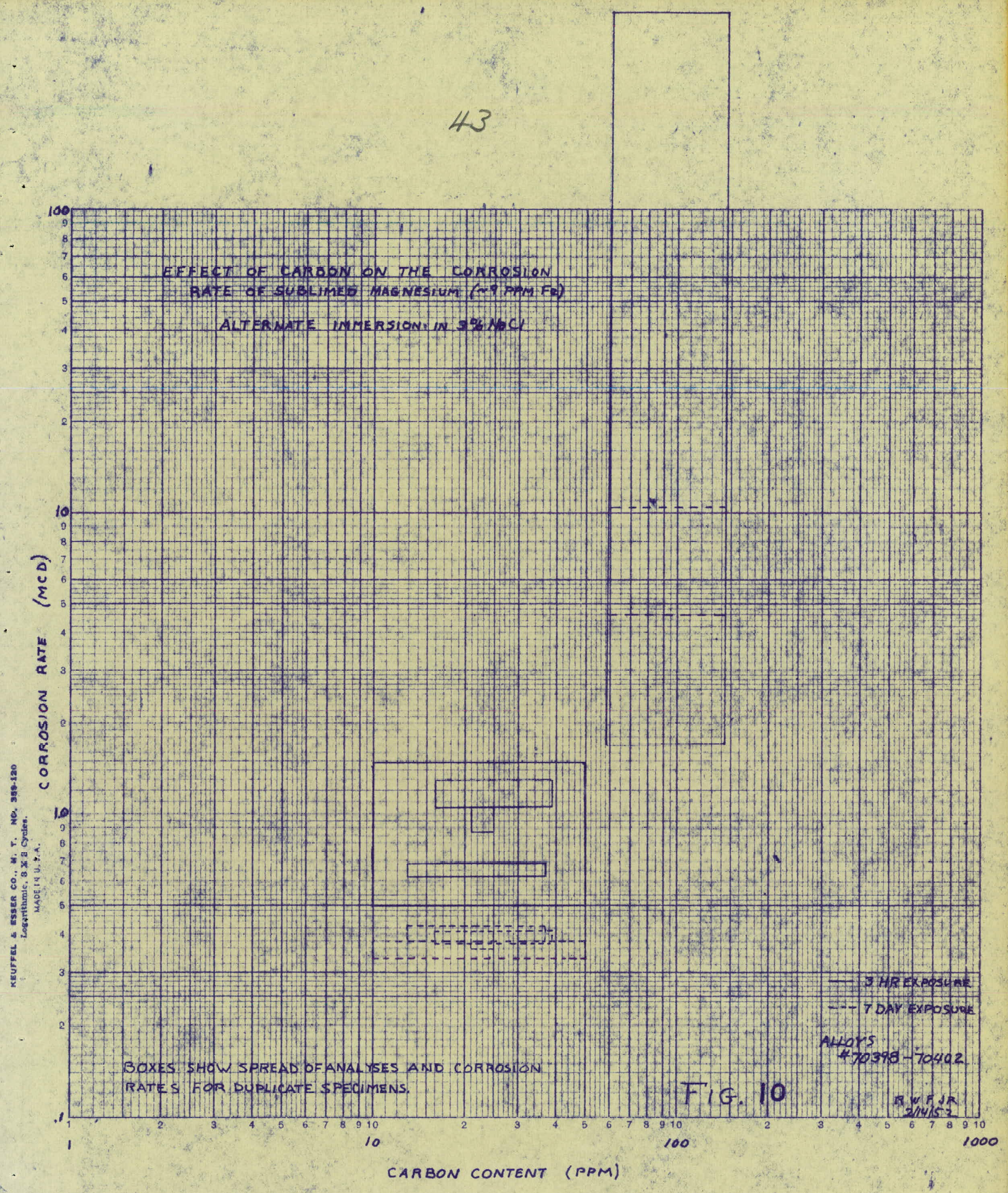




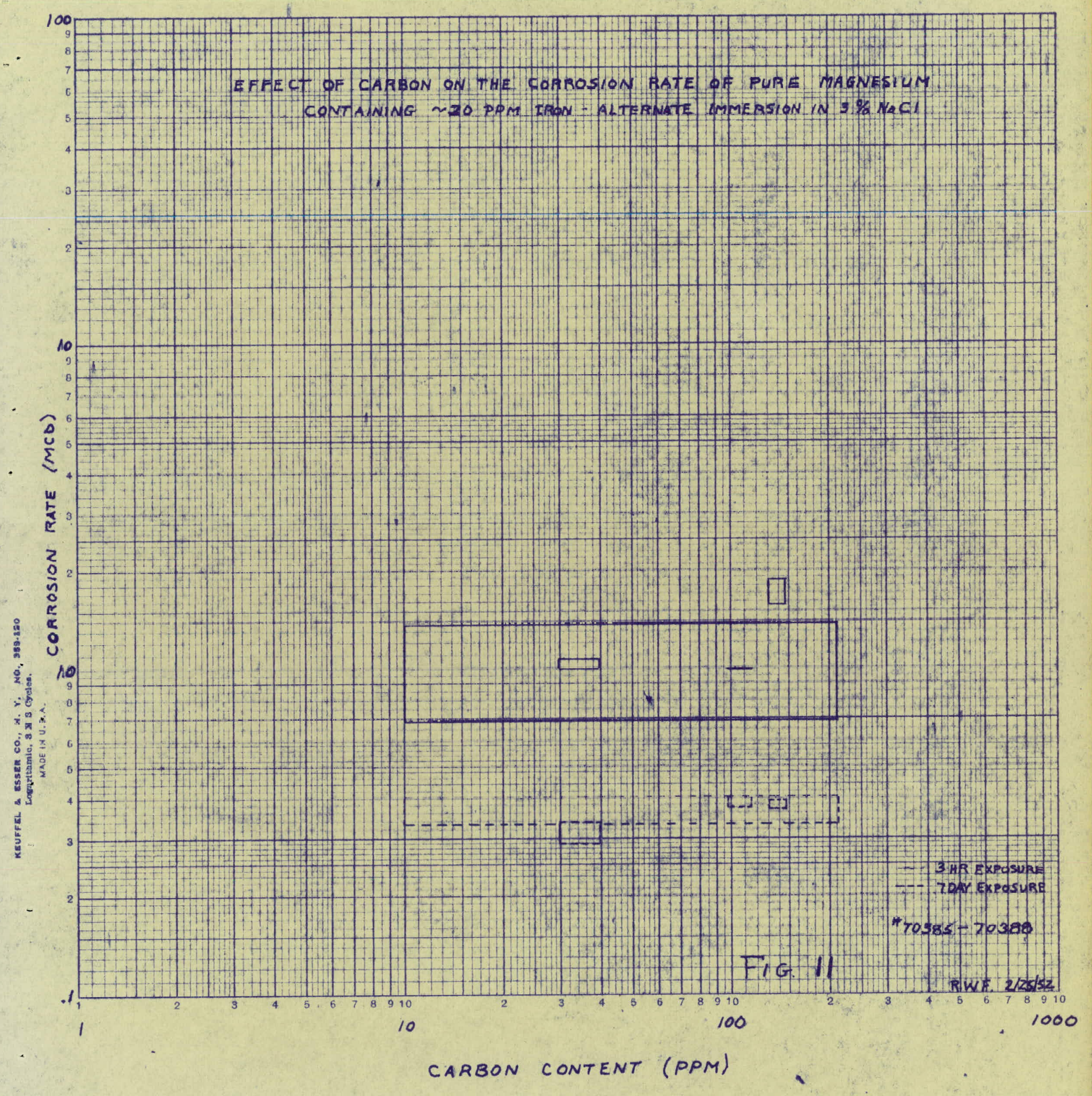




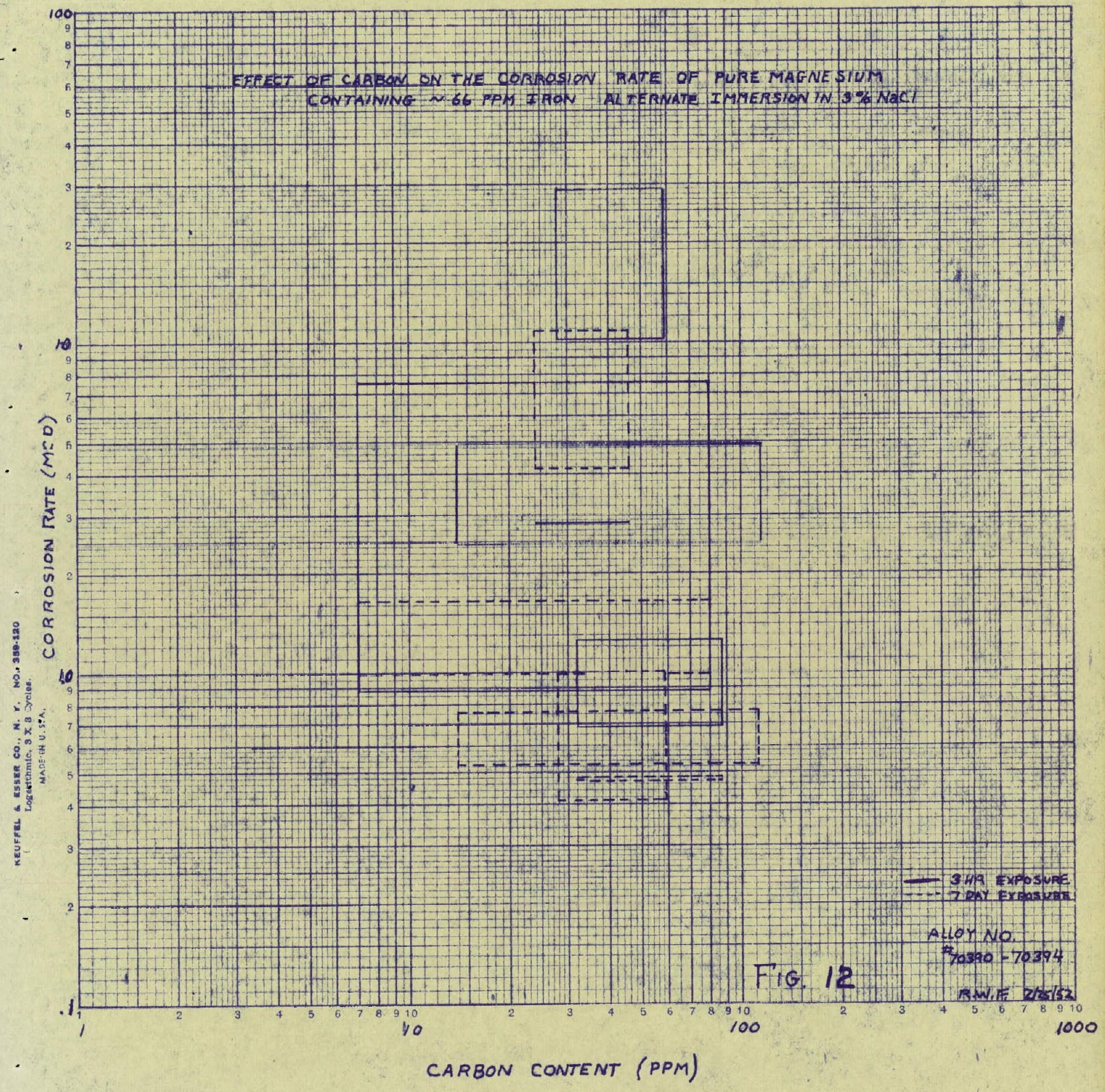


Serni-Iogarithmic, $z$ Cycles $\times 10$ to the ineh, Eth lines accentod,

46

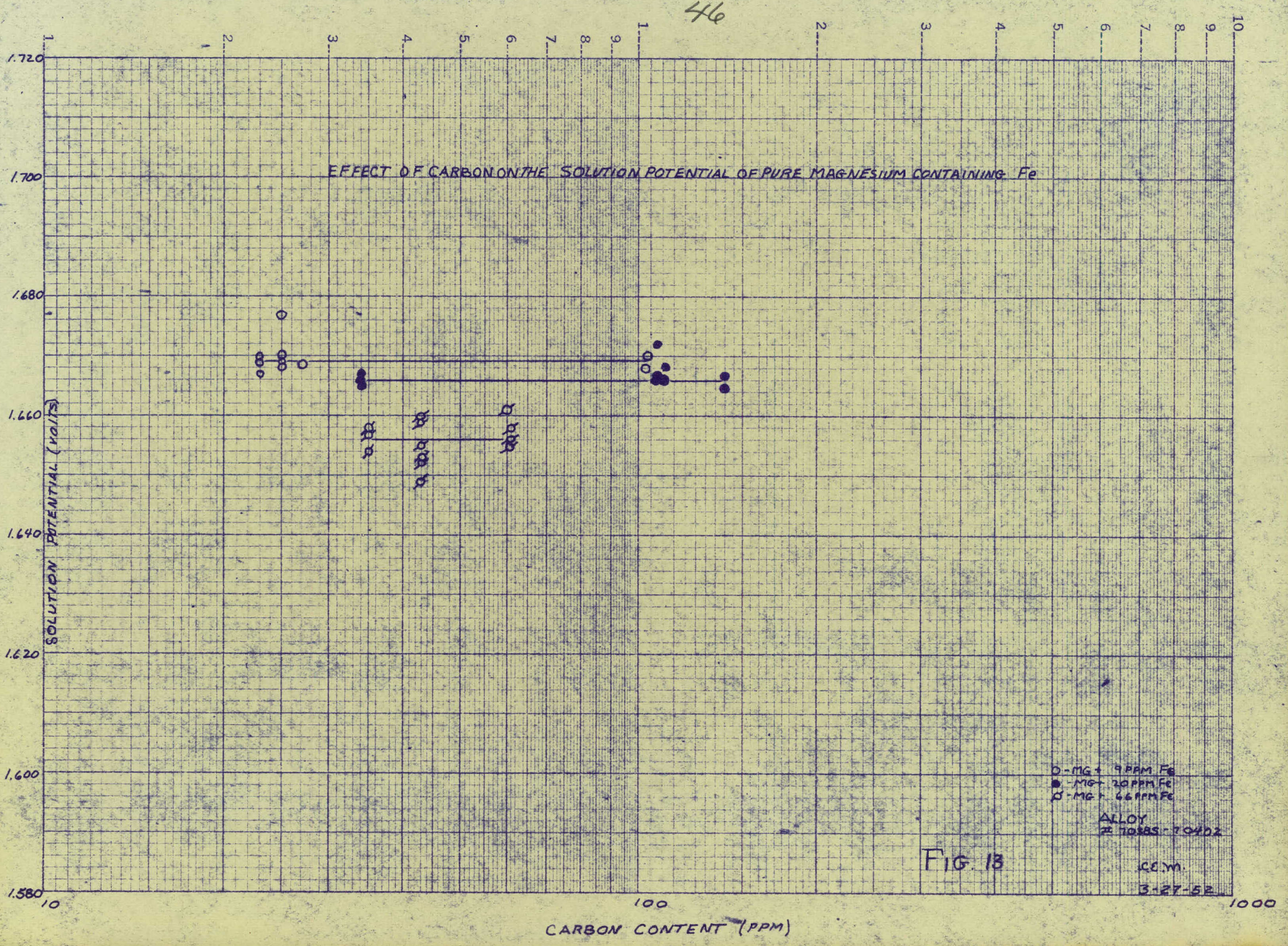




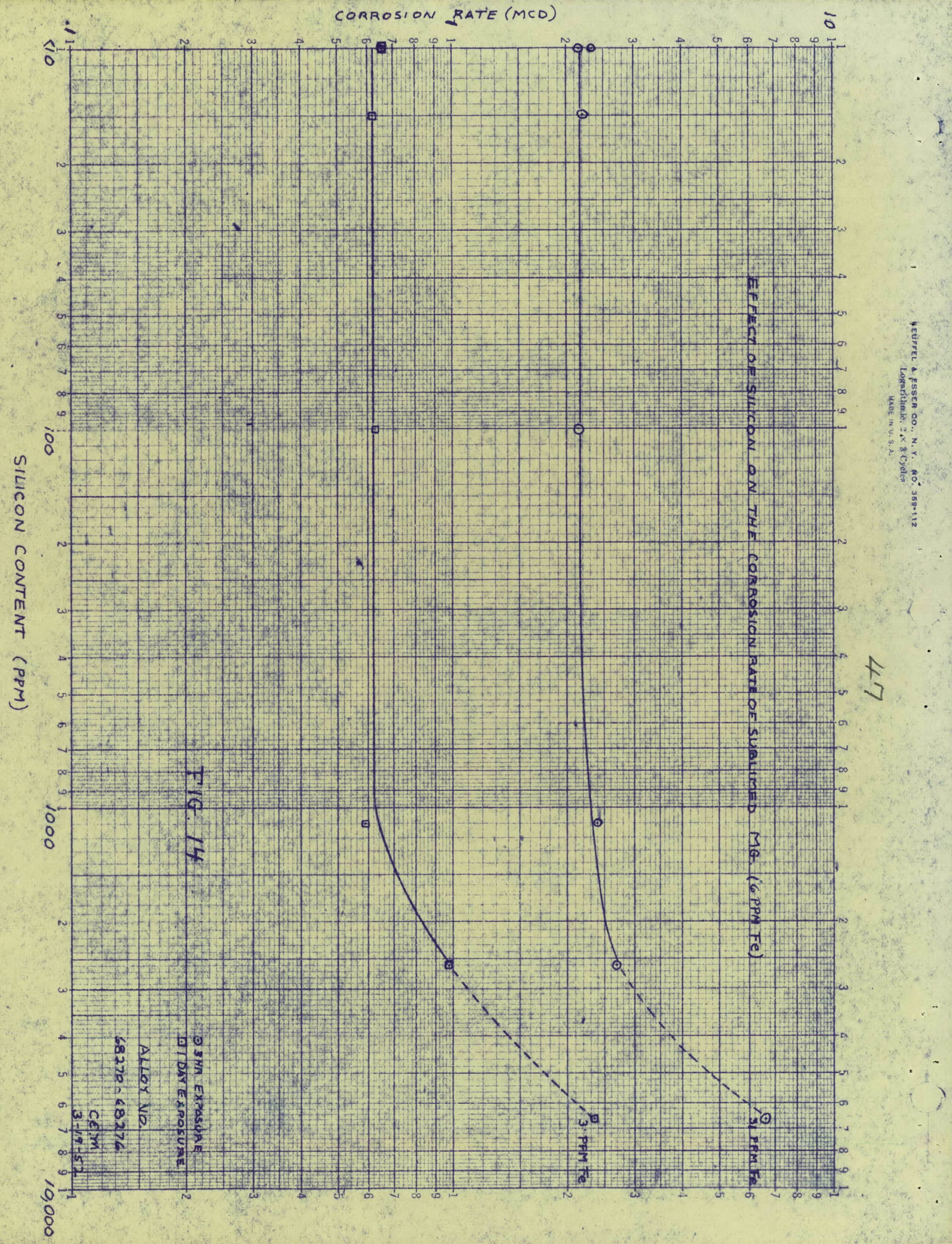




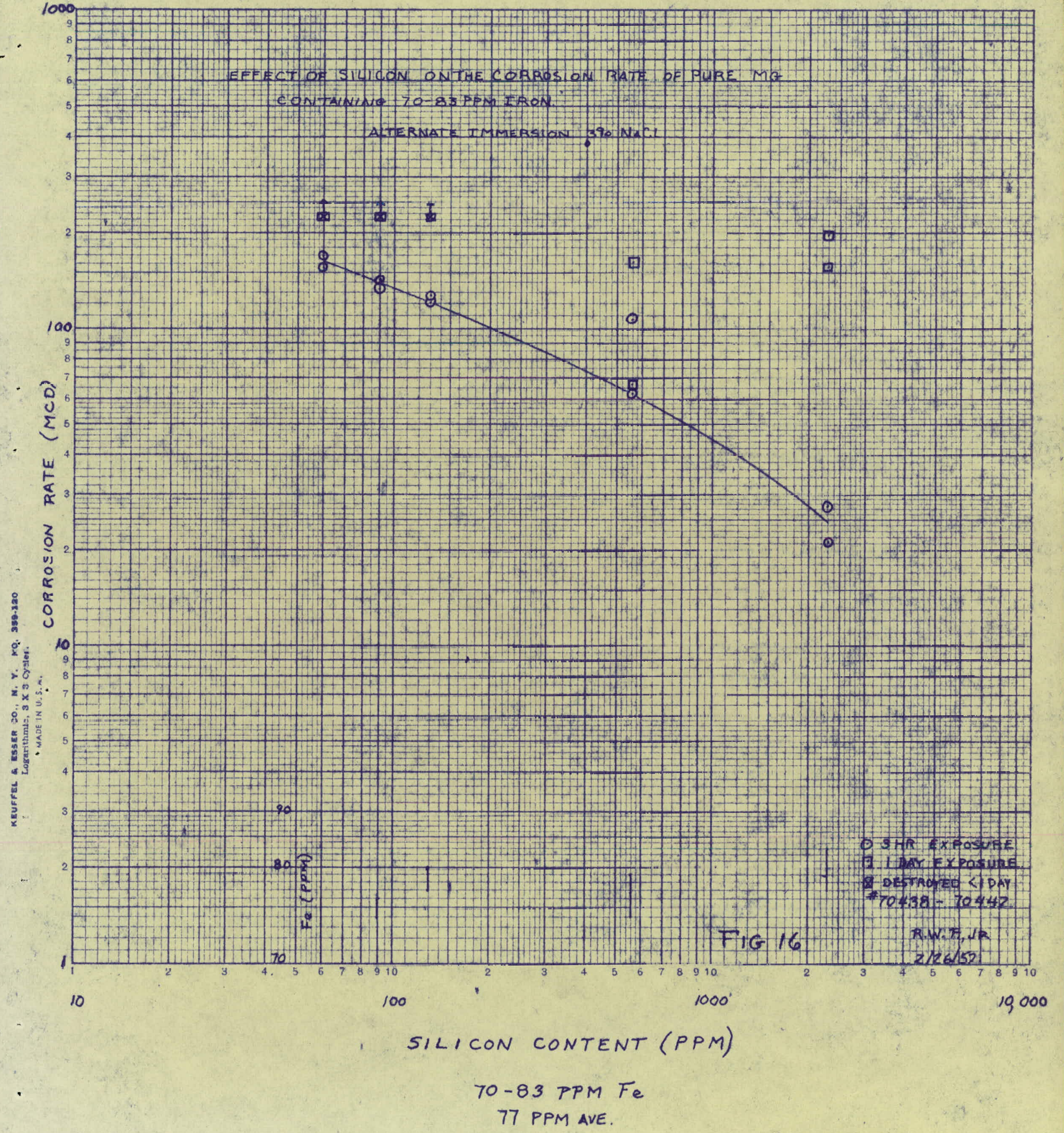




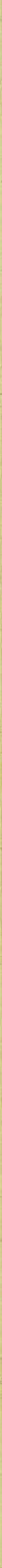




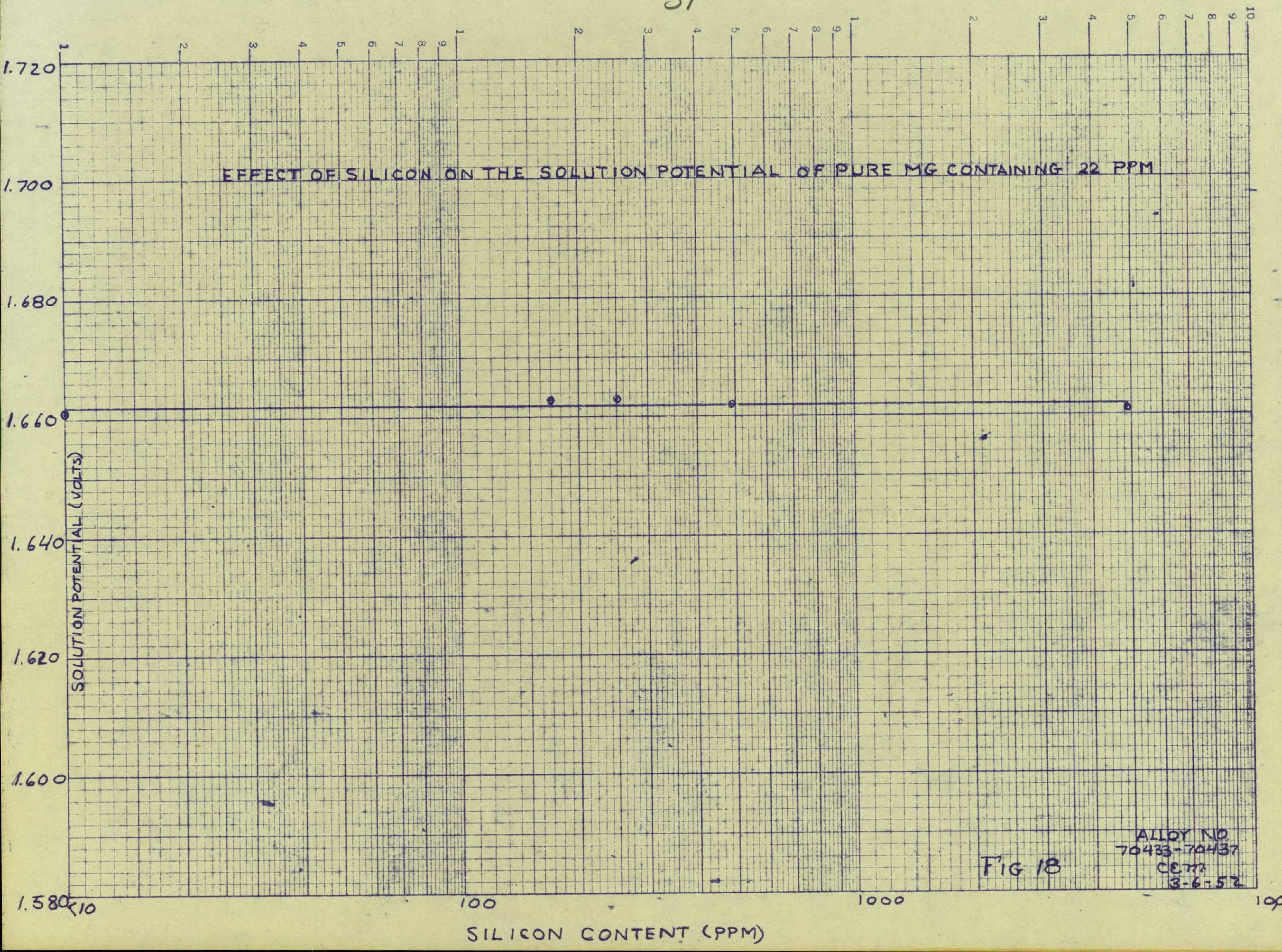




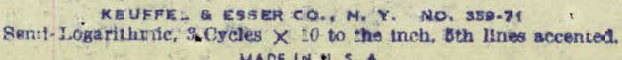

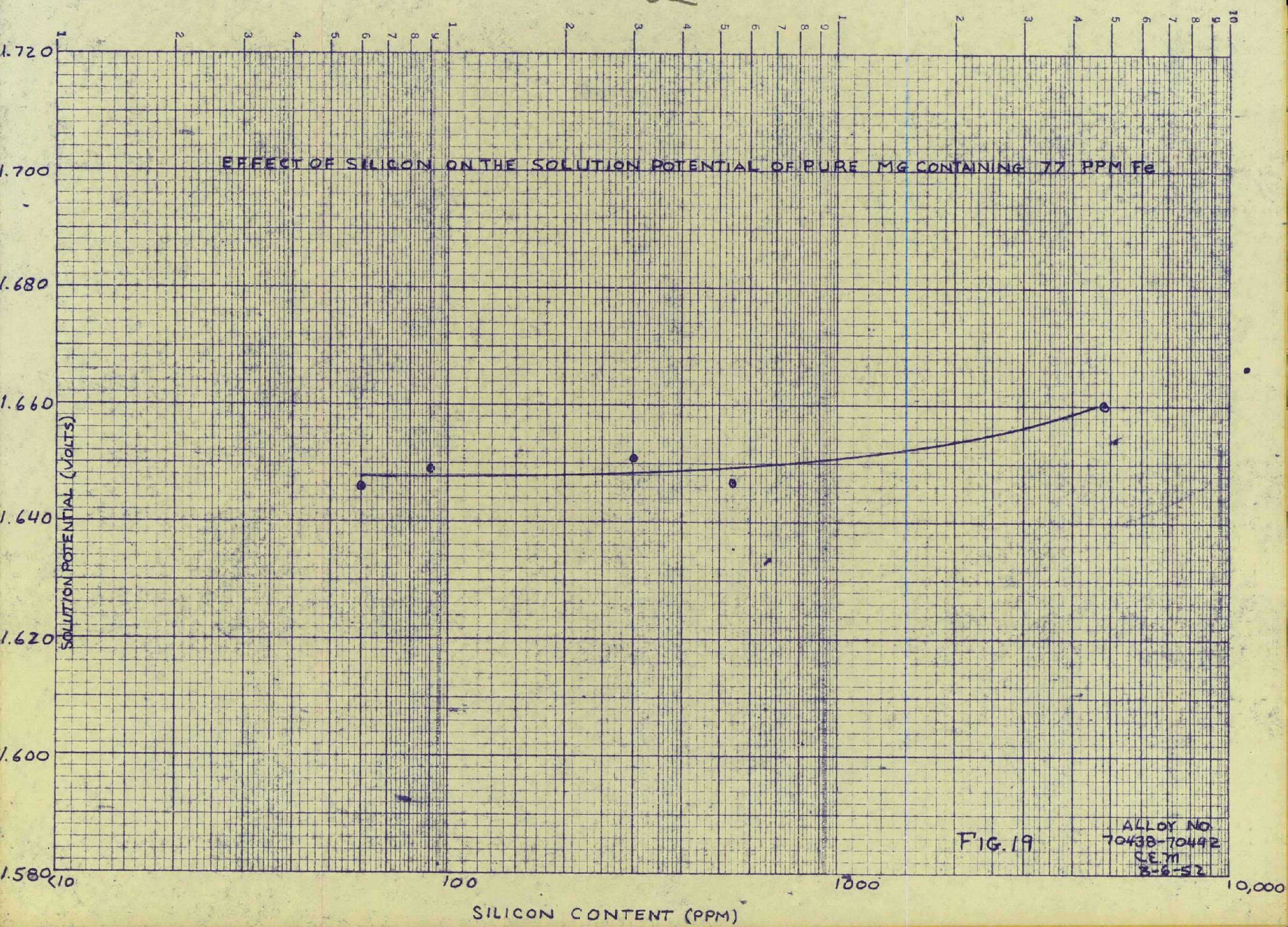




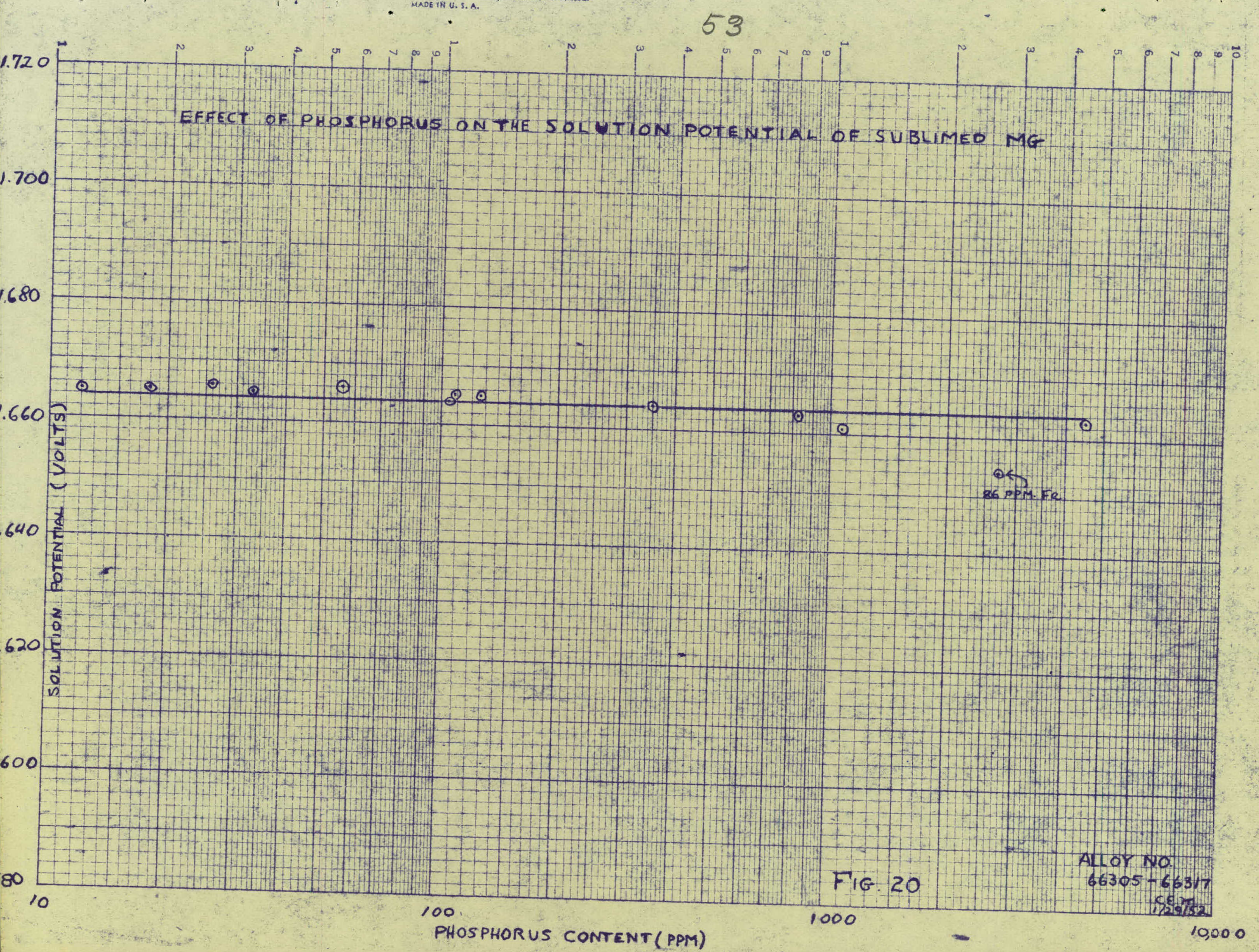



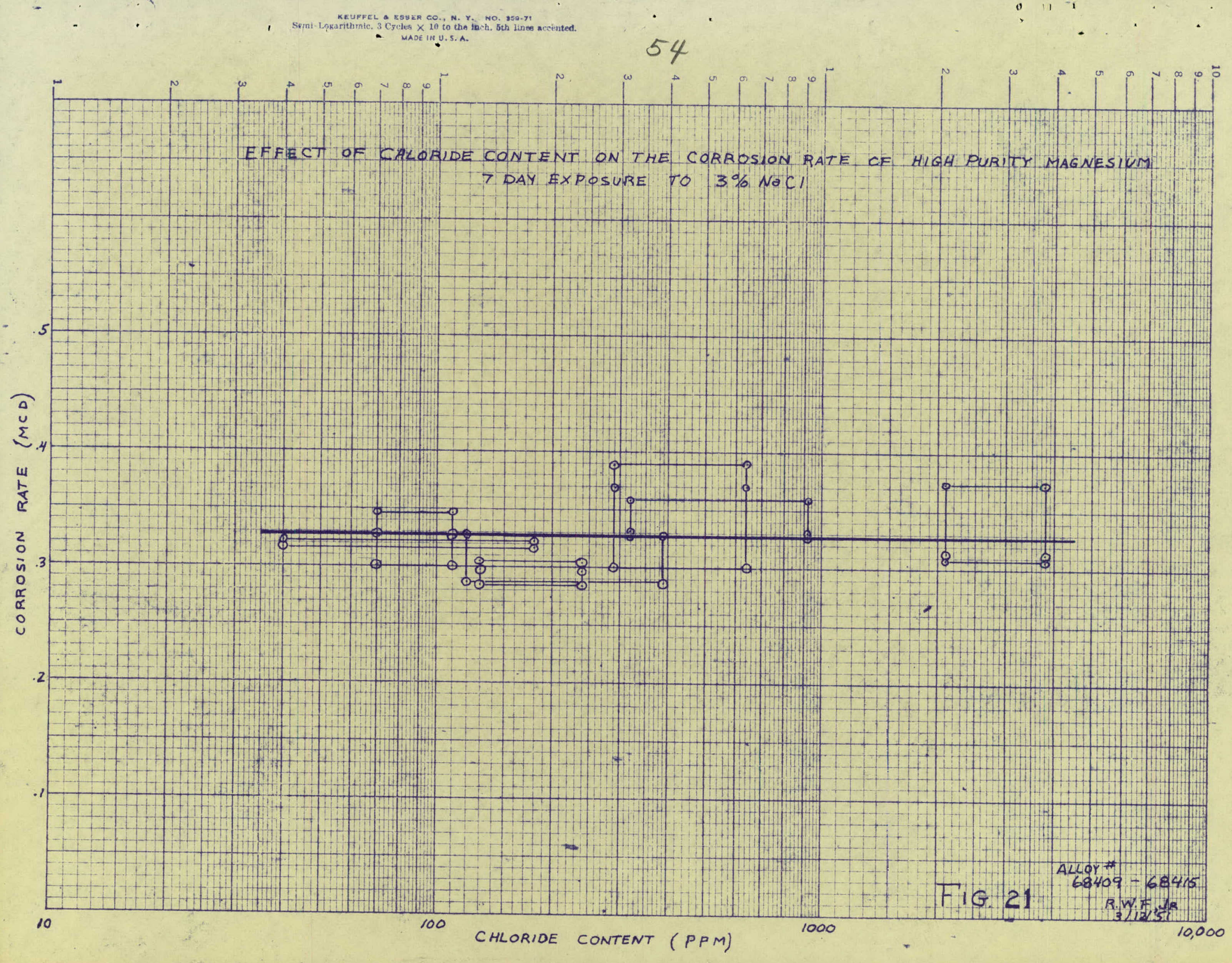
56

\section{ARC-MELTING POT}

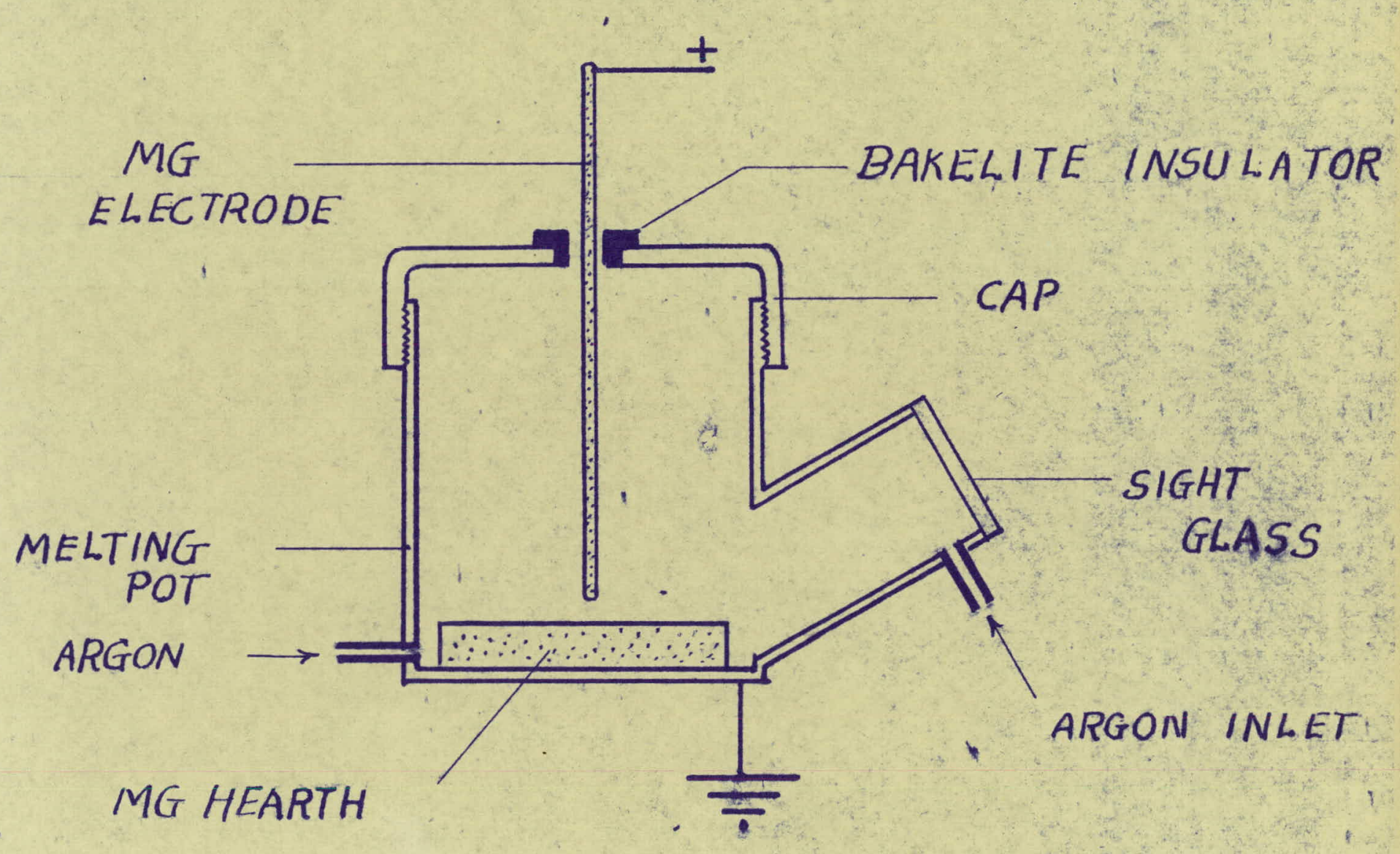

FIGURE 23 
Cooling Fate, Sublimed and Argon - Cast Magnesium.

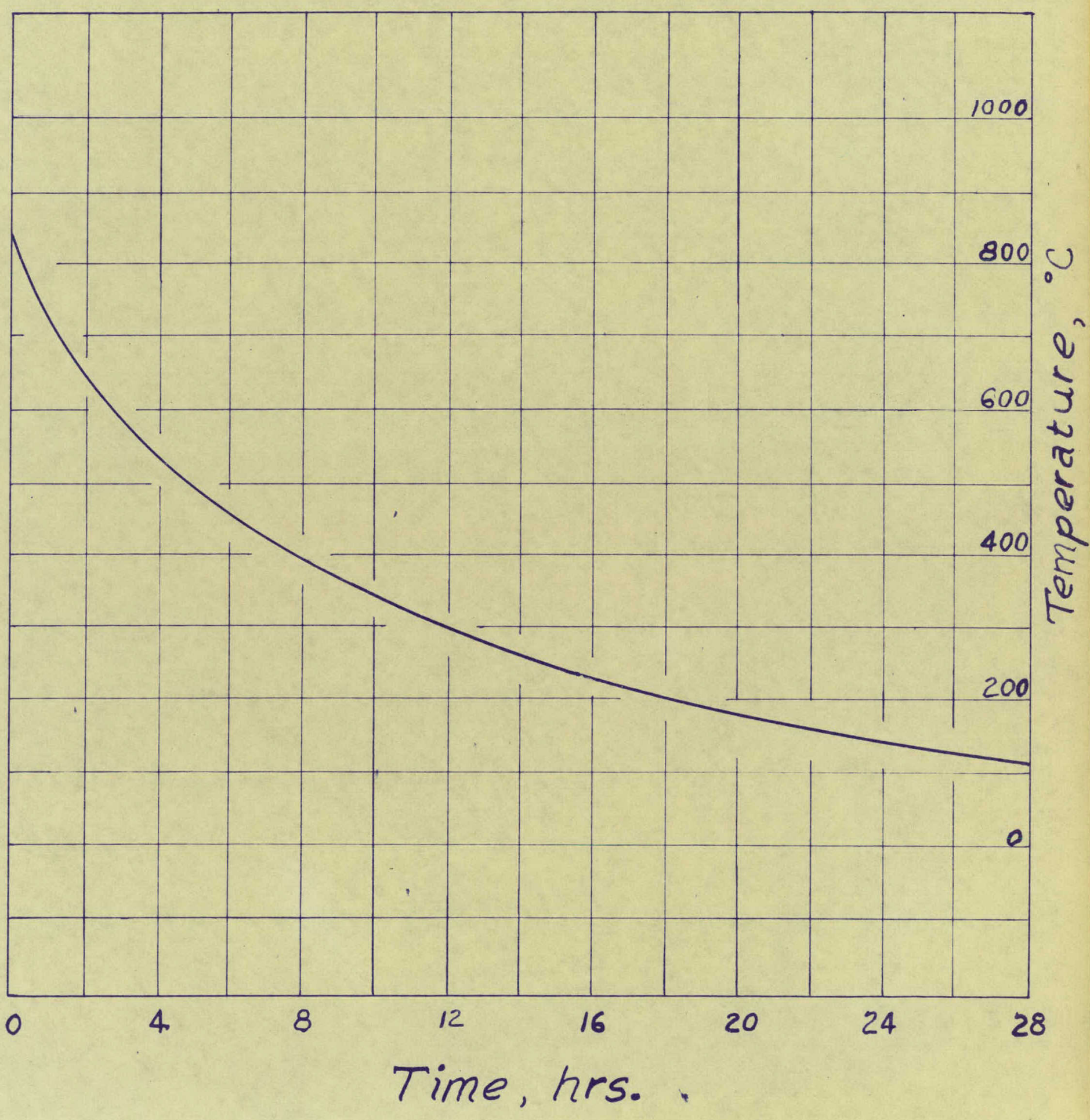

Figure 24 
Photomicrograph of Triply-Sublimed and Arc-Melted Magnesium

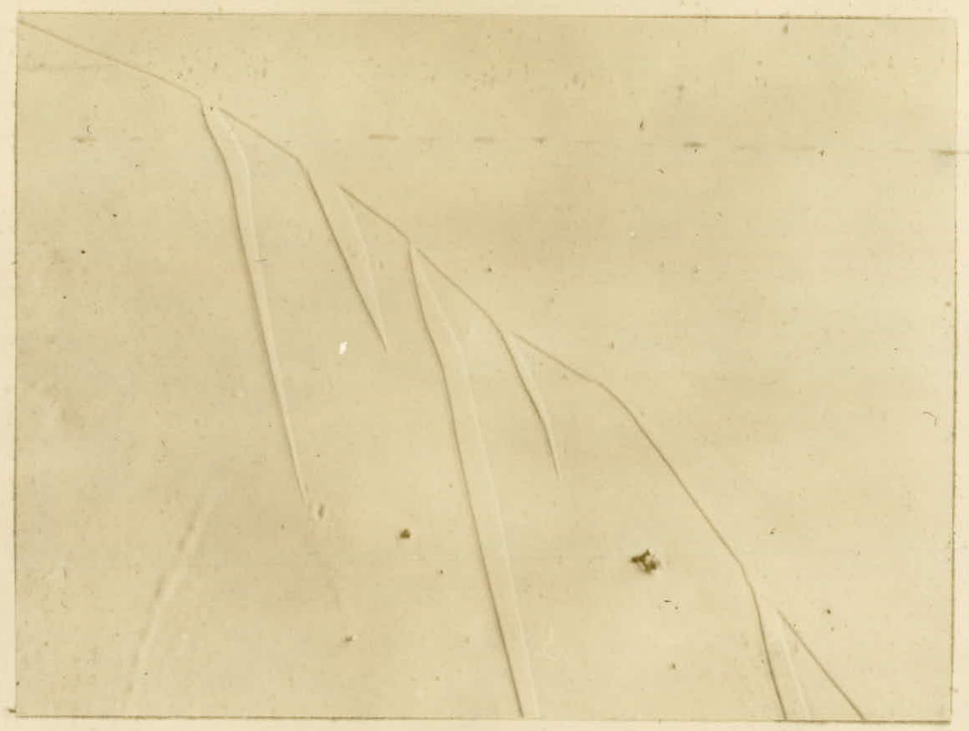

\section{$750 x$}

Alloy No. 69629-4

Electrolytically Polished. 